\title{
Joint atmospheric-terrestrial water balances for East Africa: a WRF-Hydro case study for the upper Tana River basin
}

\author{
Noah Kerandi ${ }^{1,2,3} \cdot$ Joel Arnault ${ }^{1,2} \cdot$ Patrick Laux $^{1,2} \cdot$ Sven Wagner ${ }^{1,2}$. \\ Johnson Kitheka ${ }^{3}$ • Harald Kunstmann ${ }^{1,2}$
}

Received: 11 August 2016 / Accepted: 17 January 2017 / Published online: 3 February 2017

(C) The Author(s) 2017. This article is published with open access at Springerlink.com

\begin{abstract}
For an improved understanding of the hydrometeorological conditions of the Tana River basin of Kenya, East Africa, its joint atmospheric-terrestrial water balances are investigated. This is achieved through the application of the Weather Research and Forecasting (WRF) and the fully coupled WRF-Hydro modeling system over the MathioyaSagana subcatchment $\left(3279 \mathrm{~km}^{2}\right)$ and its surroundings in the upper Tana River basin for 4 years (2011-2014). The model setup consists of an outer domain at $25 \mathrm{~km}$ (East Africa) and an inner one at 5-km (Mathioya-Sagana subcatchment) horizontal resolution. The WRF-Hydro inner domain is enhanced with hydrological routing at 500-m horizontal resolution. The results from the fully coupled modeling system are compared to those of the WRF-only model. The coupled WRF-Hydro slightly reduces precipitation, evapotranspiration, and the soil water storage but increases runoff. The total precipitation from March to May and October to December for WRF-only ( $974 \mathrm{~mm} /$ year) and coupled WRF-Hydro (940 mm/year) is closer to that derived from the Climate Hazards Group Infrared Precipitation with Stations (CHIRPS) data (989 mm/year) than from the TRMM (795 mm/year) precipitation product. The coupled WRF-Hydro-accumulated discharge $(323 \mathrm{~mm} /$ year $)$ is close to that observed $(333 \mathrm{~mm} /$
\end{abstract}

Noah Kerandi

noah.kerandi@kit.edu

1 Kalrsruhe Institute of Technology, Campus Alpin, Institute of Meteorology and Climate Research (IMK-IFU),

Kreuzeckbahnstrasse 19, 82467 Garmisch-Partenkirchen, Germany

2 Institute of Geography, University of Augsburg, Alter Postweg 118, 86135 Augsburg, Germany

3 Institute of Mineral Processing and Mining, South Eastern Kenya University, P.O. Box 170-90200, Kitui, Kenya year). However, the coupled WRF-Hydro underestimates the observed peak flows registering low but acceptable NSE $(0.02)$ and RSR (0.99) at daily time step. The precipitation recycling and efficiency measures between WRF-only and coupled WRF-Hydro are very close and small. This suggests that most of precipitation in the region comes from moisture advection from the outside of the analysis domain, indicating a minor impact of potential land-precipitation feedback mechanisms in this case. The coupled WRF-Hydro nonetheless serves as a tool in quantifying the atmospheric-terrestrial water balance in this region.

\section{Introduction}

Kenya, East Africa, is classified as a water-scarce nation (Krhoda 2006). This situation is likely to continue in the near future (Williams and Funk 2011), although there are also indications that precipitation may slightly increase (Niang et al. 2014). In a future climate projection study, Nakaegawa and Wachana (2012) found an increase of all the four components of the terrestrial water balance, i.e., precipitation, evapotranspiration, water storage, and runoff, for the particular case of the Tana River basin (TRB), Kenya. This uncertainty in Kenyan precipitation calls for improved monitoring of water resources in this region. Precipitation is considered the most critical of all the hydrometeorological variables in Kenya and East Africa in general (e.g., Endris et al. 2013). However, all the other hydrometeorogical variables are equally important as they contribute to the water resources in a given region. This calls for a comprehensive investigation of all these variables. Steps towards this direction are significant as water in its entirety is utilized in several sectors that include agriculture, hydropower, domestic, industrial, and ecological maintenance (Agwata 2005). One way to achieve this is to investigate the 
joint atmospheric-terrestrial water balance, which relates the atmospheric moisture flow to precipitation, evapotranspiration, water storage, and runoff (Eltahir and Bras 1996). Such atmospheric-terrestrial water balance studies take care of the entire regional water cycle, which is understood to be interlinked in a complex way. For instance, changes in soil moisture condition can be related to changes in precipitation through land-atmosphere feedback mechanisms (Kunstmann and Jung 2007). A better knowledge of the atmosphericterrestrial water balance will provide vital hydrometeorological information related to water resources in the considered region. We can gain this knowledge through the application of the coupled atmospheric-hydrological modeling system. Unfortunately, most studies on water balance are skewed towards the terrestrial branch (Eltahir and Bras 1996). Yet the operational nature of the water cycle in its entirety involves the terrestrial and atmospheric branches. Recognizing their coupled roles is essential in the rational application of the whole water cycle (Shelton 2009). The coupled atmospheric-hydrological modeling is considered a novel development that is a means to achieve the aforementioned. The main objective of this study, therefore, is to contribute to a better understanding of the hydrometeorology of the TRB. In particular, our study investigates the impact of the coupled atmospheric-hydrometeorological modeling system compared to only atmospheric modeling system. Our investigation will be focused on the atmospheric-terrestrial water balance variables.

Changes in soil moisture, i.e., water storage, are considered to be of great importance for water resources, climate, agriculture, and ecosystems (Yeh and Famiglietti 2008). A number of studies (e.g., Findell and Eltahir 2003; Koster et al. 2004; Anyah et al. 2008) have argued that the influence of local soil moisture changes on precipitation is largest in arid and semiarid regions dominated by convective precipitation, like Kenya. These soil moisture-precipitation interactions have been studied with the concepts of precipitation recycling ratio and precipitation efficiency (Eltahir and Bras 1996; Schär et al. 1999; Kunstmann and Jung 2007), which emphasize the significance of evapotranspiration on local precipitation. At river basin scale, both advection and evapotranspiration contribute to precipitation (Trenberth 1999). The precipitation recycling analysis allows the quantification of the interaction between the atmospheric and terrestrial water balance components.

Studies investigating these interactions are few in most regions primarily due to lack of in situ observations of hydrometeorological data such as humidity, wind, radiation, air pressure, soil moisture, evapotranspiration, and runoff. Kenya and East Africa in general are among these regions. The lack of data can be mitigated by the use of regional climate model (RCM) data for atmospheric-terrestrial water balance study (e.g., Kunstmann and Jung 2007; Music and Caya 2007; Roberts and Snelgrove 2015).
As stated by Kunstmann and Stadler (2005), the application of RCMs coupled with hydrological models is gaining scientific attention as it enhances the description of soil processes involved in the terrestrial water balance. The coupling can be said to take advantage of the nesting capabilities of the atmospheric model, which can be nested into a global model to allow large-scale integration (Bronstert et al. 2005). The coupling of atmospheric and hydrological models can be achieved through one-way, two-way, or integrated (integrative) modeling (Bronstert et al. 2005). The one-way coupling is the simplest way, in which the coupling drives the hydrological models by outputs of atmospheric models. Both hydrological and atmospheric models describe the same land surface processes, but the modeling system does not allow feedback between the two (Zabel and Mauser 2013). In a two-way coupling, the feedback is allowed, which leads to production of subgrid scale land surface fluxes and generally an improvement of model simulations (Zabel and Mauser 2013). It is argued that the coupled modeling approach has the advantage of including the soil moisture redistribution feedback in the lower boundary conditions of atmospheric models, which may lead to an improved representation of water and energy fluxes between land and atmosphere (Maxwell et al. 2011; Shrestha et al. 2014; Senatore et al. 2015; Arnault et al. 2016; Wagner et al. 2016). Maxwell et al. (2007) showed that the fully coupled modeling system yields a topographically driven soil moisture distribution and depicts a spatial and temporal correlations between surface and lower atmospheric variables and water depth. This may suggest that the fully coupled models are regulated by the geographical location of the area under study.

The coupled WRF-Hydro, a combination of the atmospheric Weather Research and Forecasting (WRF) model and a hydrological module referred to as uncoupled WRF-Hydro (Skamarock et al. 2008; Gochis et al. 2015), provides such a coupling approach. This coupled modeling system is a recent development designed to provide more accurate information related to the spatial redistribution of surface, subsurface, and channel waters across land surfaces and more importantly as an enhancement to coupling of hydrologic models with atmospheric models. Both coupled and uncoupled WRF-Hydro systems have been applied for studies in a number of places in the world (e.g., Yucel et al. 2015; Senatore et al. 2015; Arnault et al. 2016). Yucel et al. (2015) applied the model in uncoupled mode to evaluate flood forecasting over mountainous basins in the western Black Sea region of Turkey. They found the model to reasonably simulate many important features of flood events in the area. Senatore et al. (2015) used the WRF-Hydro in coupled mode over the Crati River basin, Southern Italy, and found that the coupled model showed better results in simulation of the water cycle components than the atmospheric model in stand-alone mode (WRF-only). Recently, Arnault et al. (2016) applied the coupled WRF- 
Hydro for investigating the role of runoff-infiltration partitioning and resolved overland flow on land-atmosphere feedback mechanisms over West Africa and postulated the potential of such coupled modeling system in application for joint atmospheric-terrestrial water balance studies.

These previous studies suggest that coupled atmospherichydrological modeling significantly affects the simulated atmospheric-terrestrial water balance (Maxwell et al. 2011; Senatore et al. 2015; Arnault et al. 2016; Wagner et al. 2016), especially in arid and semi-arid regions where soil moisture-precipitation interactions are largest (e.g., Findell and Eltahir 2003; Koster et al. 2004; Anyah et al. 2008). It is against this background that this study applies the coupled WRF-Hydro modeling system for the Mathioya-Sagana subcatchment (MSS) in the upper TRB, Kenya. The study region has been chosen for its location, i.e., upstream of the Masinga dam, the availability of discharge data, and its crucial role in contributing to the agricultural sector of Kenya's economy. The WRF-only and coupled WRF-Hydro models are applied to MSS for a 4-year period (2011 to 2014). Model results are used to investigate the atmospheric-terrestrial water balance and precipitation recycling over the region. The impact of the enhanced description of hydrological processes in WRF-Hydro is investigated by comparing WRF-Hydro and WRF results with observations.

Section 2 provides a brief description of the study area, models, experimental design, data, and methodology. Results are given in Sect. 3, followed by a summary and conclusion of our results in Sect. 4.

\section{Study area, models, data, and methodology}

\subsection{The study area}

The Mathioya-Sagana subcatchment (MSS) is a portion uppermost of the upper Tana River basin (TRB) catchment. More specifically, it lies between $0^{\circ} 10^{\prime \prime}$ and $0^{\circ} 48^{\prime \prime} \mathrm{S}$ and $36^{\circ} 36^{\prime \prime}$ and $37^{\circ} 18^{\prime \prime} \mathrm{E}$ (Fig. 1a; see the red contour boundary) covering an area of approximately $3279 \mathrm{~km}^{2}(\approx 20.5 \%$ of the entire upper TRB). The upper TRB is about $16,000 \mathrm{~km}^{2}$ (Wilschut 2010) with elevation of between $400 \mathrm{~m}$ a.s.l. (on the eastern part of the catchment) and 5199 m.a.s.l. on Mount Kenya (Geertsma et al. 2009). The MSS, in particular, has an elevation of between 1000 and $4700 \mathrm{~m}$ a.s.l. It is served by a number of tributaries most of them perennial that include Sagana, Ragati, New Chania, Amboni, Mathioya, Gura, Gakira, and Rukanga. All these tributaries are part of the Tana River drainage network that has its source at the slopes of Mount Kenya and the Aberdare Ranges. Tana River is the longest river in Kenya stretching about $1012 \mathrm{~km}$ with an annual mean discharge of $5 \times 10^{12} \mathrm{~m}^{3}$ (Agwata 2005). The river network of the MSS contributes remarkably to the Tana River network.
This is because these rivers are upstream of the entire Tana River network. Besides, they are just in the vicinity of the sources of Tana River itself, i.e., Mt. Kenya and the Aberdare Ranges. The Rukanga River is most downstream of all these tributaries with the river gauge station (RGS $4 \mathrm{BE} 10 ; 0^{\circ} 43^{\prime \prime} 53^{\prime \prime} \mathrm{S}, 37^{\circ} 15^{\prime \prime} 29^{\prime \prime} \mathrm{E}$ ) located at the outlet of MSS. The Tana Rukanga's RGS 4BE10 discharge is used for calibration and evaluation of the relevant model in this study.

The study area (MSS and the surrounding area; Fig. 1), like most parts of East Africa, receives its rainfall in two seasons during March, April, and May (MAM) and October, November, and December (OND) locally known as the "long rains" and "short rains," respectively, due to the south-north oscillation of the Intertropical Convergence Zone (ITCZ) (Kitheka et al. 2005; Nakaegawa and Wachana 2012; Oludhe et al. 2013). The mean annual rainfall ranges between 960 and $1200 \mathrm{~mm}$, while climatologically, the region experiences low annual/monthly mean temperatures of about $17^{\circ} \mathrm{C}$ or less (Kerandi et al. 2016). According to the Moderate Resolution Imaging Spectroradiometer (MODIS, 20 classes; Friedl et al. 2002) based land use classification, the dominant land use classes are the evergreen broadleaf forest and the savannas and woody savannas (Fig. 1b).

\subsection{Model description and the experimental design}

The fully coupled modeling system used in this study consists of two models, the Weather Research and Forecasting (WRF) model whose details are described by Skamarock et al. (2008; details are also available online at http://www.wrf-model.org) and its hydrological extension package referred to as WRFHydro (Gochis et al. 2015; details can also be found online at https://www.ral.ucar.edu/projects/wrf_hydro). The WRF model is a non-hydrostatic, mesoscale Numerical Weather Prediction (NWP) and atmospheric simulation system. It is designed with a flexible code and offers several physical options (parameterizations) to choose from. In addition, the WRF-Hydro facilitates coupling of multiple hydrological process representation together. It is purposed to account for land surface states and fluxes and provides physically consistent land surface fluxes and stream channel discharge information for hydrometeorological applications. A brief overview of the experimental design of these two models and the coupling process is discussed in Sects. 2.2.1 and 2.2.2.

\subsubsection{Weather Research and Forecasting model}

In this study, WRF version 3.5.1 was used for all experiments. Details of the WRF physics schemes and experimental details for this study are shown in Table 1 and explained in more details by Kerandi et al. (2016).

Two one-way nest domains with the larger domain, D1 at $25-\mathrm{km}$ and D2 at 5-km horizontal resolution, are considered 


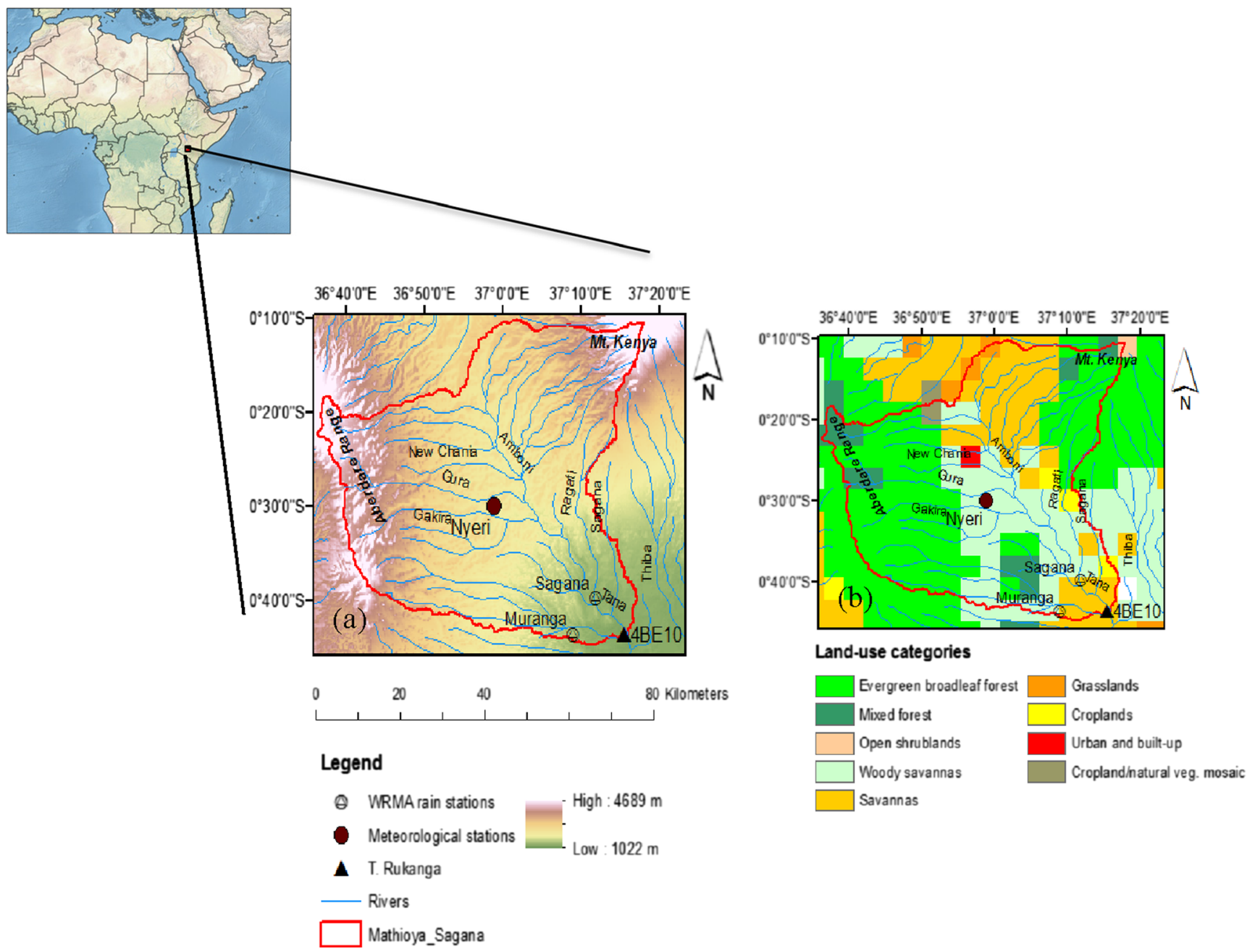

Fig. 1 a Map of study area and the location of one meteorological station (Nyeri), two rain stations ( Sagana, Murang'a), and one discharge gauge (black triangle; Tana Rukanga's RGS 4BE10). Red contour marks the Mathioya-Sagana subcatchment (MSS) in the northwest of the upper Tana River basin (TRB), Kenya. Also shown is the digital elevation

for this study. D1 is defined with $140 \times 120$ grid points eastwest and north-south directions, respectively, and extends $12^{\circ}$ $\mathrm{S}-13^{\circ} \mathrm{N} ; 22^{\circ}-53^{\circ} \mathrm{E}$. $\mathrm{D} 2$ is defined with $121 \times 121$ grid points covering $3^{\circ} 3^{\prime \prime} 42^{\prime \prime} \mathrm{S}-2^{\circ} 17^{\prime \prime} 18^{\prime \prime} \mathrm{N} ; 34^{\circ} 33^{\prime \prime} 43^{\prime \prime}-39^{\circ} 54^{\prime \prime} 50^{\prime \prime}$ E encompassing the whole of upper TRB (Fig. 2). D2 is additionally coupled with routing process at 500-m resolution with $1200 \times 1200$ grid points east-west and north-south directions, respectively. The fully coupled simulations together with the routing processes (explained in Sect. 2.2.2) are based on $\mathrm{D} 2$.

The simulations are initialized on November 1, 2010, including a spin-up period of 2 months and cover a 4 -year period from 2011 to 2014 . The model domains use 40 vertical levels up to $20 \mathrm{hPa}$ (approximately 26-km vertical height above the surface). ERA-Interim reanalysis (Dee et al. 2011) provides the initial and lateral boundary conditions for the simulations. model (DEM; derived from the 3" (90 m) USGS HydroSHEDS at 500$\mathrm{m}$ resolution) and river network in the study area (b) dominant land use categories in the study area based on the Moderate Resolution Imaging Spectroradiometer (MODIS) at 30" resolution. Map of Africa (top left) is processed from Natural Earth data; www.naturalearthdata.com)

\subsubsection{Weather Research and Forecasting-Hydro}

The WRF-Hydro model permits a physics-based, fully coupled land surface hydrology-regional atmospheric modeling capability for use in hydrometeorological and hydroclimatological research applications (Gochis et al. 2015). The model can be used both in an uncoupled (standalone or offline) mode and in a coupled mode to an atmospheric model and other Earth System modeling architectures.

In uncoupled mode, its land surface model (in our case, the Noah land surface model (Noah LSM)) acts like any land surface hydrological modeling system. It requires meteorological forcing data prepared externally and provided as gridded data. This is the uncoupled WRF-Hydro used for the calibration in Sect. 3.1. Otherwise, the enhanced description of hydrological processes in uncoupled WRF-Hydro is the same as that in the coupled mode. 
Table 1 The experimental details of the atmospheric model, WRF

\begin{tabular}{lll}
\hline Subject & Chosen option & Reference \\
\hline Driving data & ERA-Interim & Dee et al. (2011) \\
Horizontal resolution & $25 \mathrm{~km}, 5 \mathrm{~km}$ & \\
Horizontal grid number & $140 \times 120,121 \times 121$ & \\
Integration time-step & $100 \mathrm{~s}$ for D1 & \\
Projection resolution & Mercator & \\
Simulation period & November 1, 2010, to December 31, 2012 & \\
Vertical discretization & 40 layers & \\
Pressure top & 20 hPa & Kain (2004) \\
WRF output interval & $24 \mathrm{~h}$ & Hong et al. (2006) \\
Cumulus convection & Kain-Fritsch (KF) & Pleim (2007) \\
Microphysics scheme & WRF Single-Moment 6-class (WSM6) & Chou and Suarez (1999) \\
Planetary boundary layer & Asymmetric Convection Model (ACM2) & \\
Longwave radiation & New Goddard & Chen and Dudhia (2001) \\
Shortwave radiation & & Friedl et al. (2002) \\
Land surface scheme & Noah LSM & Monin and Obukhov (1954) \\
Land use & MODIS & \\
Surface layer & MM5 similarity &
\end{tabular}

In its coupled mode, WRF-Hydro generally leads to an improved simulation of the full regional water cycle with its capability of permitting atmospheric, land surface, and hydrological processes from available physics options. Such options are referred to as routing processes and include surface overland, subsurface, channel, and conceptual baseflow (bucket model). The routing time step is set in accordance with the routing grid spacing (Gochis et al. 2015). In this study, all these routing processes have been activated and hence contribute to the simulated discharge. Four soil layers are used: $0-10,10-40,40-100$, and 100 $200 \mathrm{~cm}$. In this mode, the WRF model provides the required meteorological forcing data with a frequency dictated by the Noah LSM time step specified for D2 (in our case, 20s). This enhances the interaction between the hydro model components with the Noah LSM and WRF model physics. Specific details relevant to the WRF-Hydro are provided in Table 2.
Fig. 2 Map of East Africa showing the location of model domains at 25- and 5-km horizontal resolution (D1 in black and D2 in pink box, respectively). D1 is defined by $140 \times 120$ grid points and extends $12^{\circ} \mathrm{S}-13^{\circ} \mathrm{N}$; $22^{\circ}-53^{\circ} \mathrm{E}$, and $\mathrm{D} 2$ is defined by $121 \times 121$ grid points covering $3^{\circ}$ 3" 42" S-2 $17^{\prime \prime} 18^{\prime \prime} \mathrm{N} ; 34^{\circ} 33^{\prime \prime}$ $43^{\prime \prime}-39^{\circ} 54^{\prime \prime} 50^{\prime \prime}$ E encompassing the whole of upper TRB (inset red contour). Blue contour shows the boundary of the entire TRB

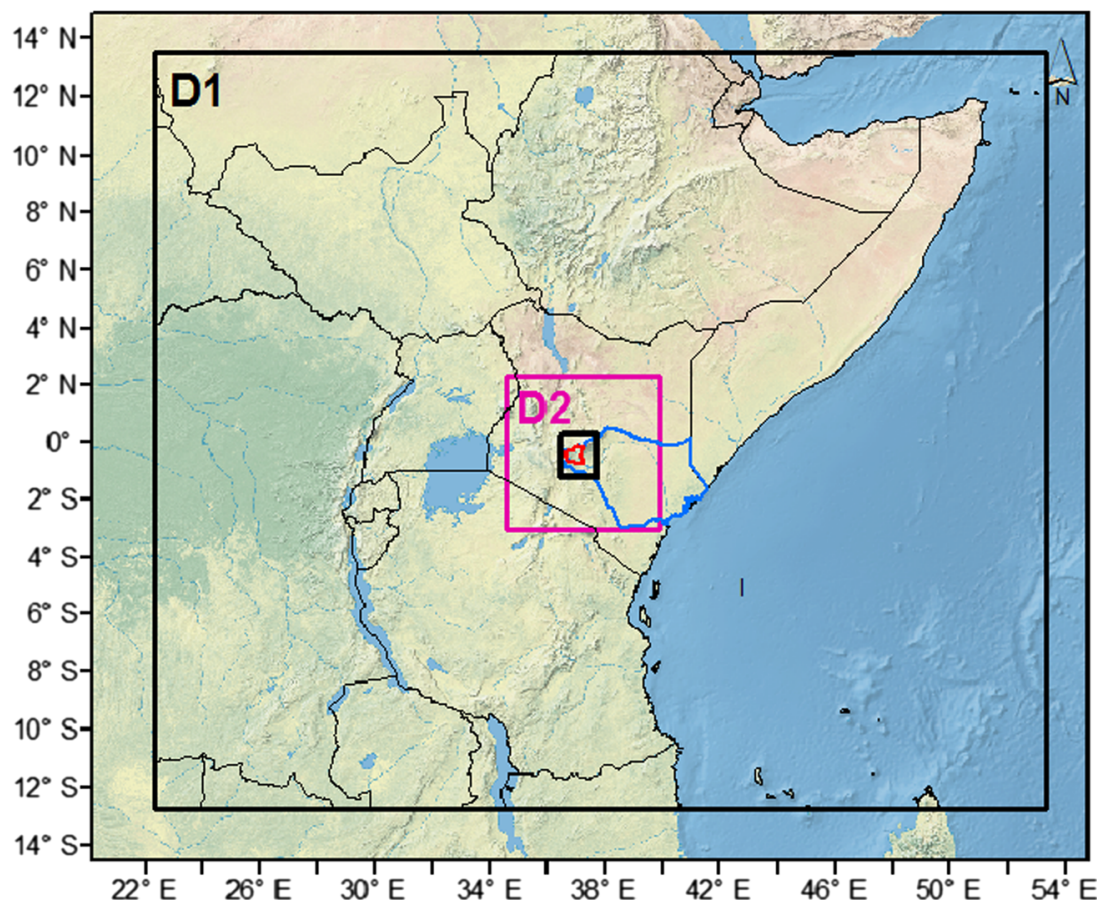


Table 2 The experimental details specific to uncoupled/coupled WRFHydro

\begin{tabular}{ll}
\hline Subject & Chosen option \\
\hline Nest identifier & 2 \\
Hydro output interval & $360 \mathrm{~min}(6 \mathrm{~h})$ \\
Model subgrid size (routing grid space) & $500 \mathrm{~m}$ \\
Integer divisor (aggregation factor) & 10 \\
Routing model time step & $20 \mathrm{~s}$ \\
Physics options/parameterizations & \\
Subsurface routing & Yes \\
Overland flow routing & Yes \\
Channel routing & Yes with steepest descent \\
Baseflow bucket model & Yes with pass-through \\
\hline
\end{tabular}

In coupled WRF-Hydro, the hydrological component is called directly from WRF in the WRF surface driver module. This is accomplished at the coupling interface by the WRFHydro coupling interface module. The interface serves to pass data, grid, and time information between WRF and WRFHydro. The WRF-Hydro components map data and subcomponent routing processes (e.g., land and channel routing). Upon completion of these processes, the data is remapped back to the WRF model (by the WRF-Hydro driver) through the coupling interface. The details of these routing processes are available in literature (e.g., Gochis et al. 2015; Senatore et al. 2015).

\subsection{Observational and gridded datasets}

\subsubsection{Precipitation and discharge}

The satellite estimates of the Tropical Rainfall Measuring Mission (TRMM, 3B42 v7 derived daily at $0.25^{\circ}$ horizontal resolution, 1998 to 2015; Huffman et al. 2007), the station rainfall, and discharge from the Tana Rukanga's RGS 4BE10 are used. In addition, the Climate Hazards Group Infrared Precipitation with Stations (CHIRPS; CHIRPS v2.0 at $0.05^{\circ}$ horizontal resolution; 1981-near present; Funk et al. 2015), a recent global dataset available to the public, is used. Like TRMM, it has a spatial coverage spanning $50^{\circ} \mathrm{S}-$ $50^{\circ} \mathrm{N}$ (and all longitudes). CHIRPS dataset is based on satellite imagery with in situ station data, and it provides a daily resolution. It is designed as a suitable alternative for datasparse regions characterized by convective rainfall. Details on CHIRPS can be found at http://chg.geog.ucsb. edu/data/chirps/

Figure 3 shows the mean annual evolution of monthly precipitation (based on CHIRPS, TRMM, and station rainfall) and discharge averaged for 2011 to 2014. The subcatchment, like the rest of the TRB, experiences bimodal precipitation and discharge patterns (Maingi and Marsh 2002; Oludhe et al.
2013). It is observed that the peak month for the rains over MSS occurs during April and November. In the case of the MAM season, the peak flows occur 1 month later than that of precipitation, i.e., May, while it is in agreement during the OND season.

The seasonality of stream flow is largely influenced by precipitation over the subcatchment. In terms of the annual cycle of discharge, there is a closer agreement with both CHIRPS and TRMM datasets than gauge rainfall. With the significance threshold set at 0.05 here and in all tests in this study, the monthly time series for CHIRPS and TRMM have a significant relationship with discharge [correlation coefficient $r(44)=0.72$ and $r(44)=0.75, p<0.001$, respectively]. Here, the number in parentheses shows the "degrees of freedom" defined by $n-2$ where " $n$ " is the number of data (sample size). The measured discharge that is observed and recorded at the Tana Rukanga RGS 4BE10 corresponds to only 46 months. The rainfall from the gauge manages a corresponding significant relationship with discharge of $r$ $(44)=0.57$ and $p<0.001$. This could be attributed to the coverage of the gauge rainfall, which comes from only three stations and which is not fully representative for the whole subcatchment unlike CHIRPS and TRMM data, which takes averaged values over the whole subcatchment. In general, however, the gauge rainfall and TRMM over MSS agree very closely in terms of their annual and interannual variability consistent with previous studies (e.g., Kerandi et al. 2016). This is also the case with CHIRPS datasets compared with the gauge rainfall $(r(44)=0.92, p<0.001)$. In general, there is a reasonable agreement with the gauge data and that of TRMM and CHIRPS as seen from the amount of precipitation that each yields based on the average rainfall from the three stations of Nyeri, Sagana, and Murang'a for 4 years, i.e., gauge rainfall of $1086 \mathrm{~mm} /$ year, TRMM with $1085 \mathrm{~mm} /$ year, and CHIRPS with $1124 \mathrm{~mm} /$ year. On the other hand, TRMM and CHIRPS are correlated very well $(r(44)=0.94$, $p<0.001)$. Therefore, depending on the purpose, any of these gridded datasets can substitute the station data.

\subsection{Water balance computation: theory}

The water balance refers to a conceptual structure supporting a quantitative assessment of moisture supply and demand relationships at the land-atmosphere interface on a daily, weekly, monthly, or annual basis (Shelton 2009). This gives rise to what is commonly referred to as the terrestrial and atmospheric branches of the water balance. At the land-atmosphere interface, the loss or "output" of water from the earth's surface through evaporation and evapotranspiration is the input for the atmospheric branch, whereas for precipitation, the atmospheric output is considered an input or the gain of the terrestrial branch as in Peixoto and Oort (1992). Details of the water balance computation are available in many textbooks as in 
Fig. 3 Mean annual cycle of monthly precipitation and discharge averaged for the period 2011 to 2014 at the locations of the stations (Nyeri, Sagana,

Murang'a for precipitation; Tana Rukanga's RGS 4BE10 for discharge). TRMM- and CHIRPS-derived precipitation at the locations of the stations is also displayed

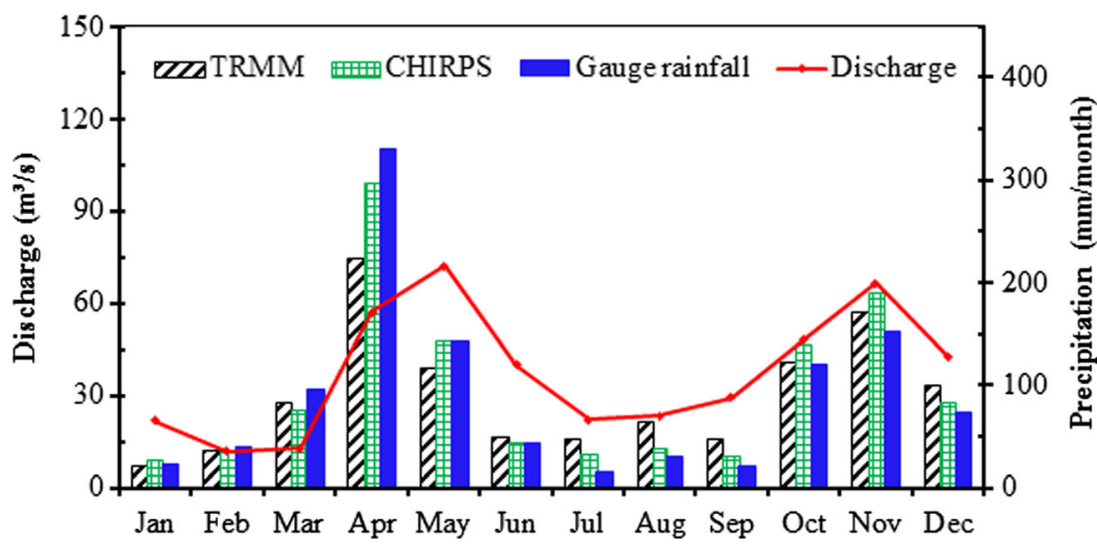

Peixoto and Oort (1992). In this section, a brief account of the relationship of terrestrial and atmospheric water balance components is provided.

\subsubsection{Terrestrial water balance computation}

The terrestrial water balance (TWB) can be written as follows:

$$
\begin{gathered}
\frac{d S}{d t}=R_{\text {in }}-R_{\text {out }}-\mathrm{ET}+P \\
=-R-\mathrm{ET}+P
\end{gathered}
$$

where $\frac{d S}{d t}$ is the total change of terrestrial water storage (S in $\mathrm{mm})$, Rin and Rout are the inflow and outflow of surface runoff, respectively, which constitute total runoff $R$ ( $\mathrm{mm} /$ day) (according to Oki et al. 1995, $R$ is simply outflow minus inflow), ET (mm/day) is the evapotranspiration, and $P(\mathrm{~mm} /$ day) is the precipitation. It is noted that in Eq. 1, each term is spatially averaged over the study area that encompasses the MSS.

\subsubsection{Atmospheric water balance computation}

The atmospheric water balance (AWB) components are related as follows:

$$
\begin{aligned}
\frac{d W}{d t} & =\mathrm{IN}-\mathrm{OUT}+\mathrm{ET}-P-\varepsilon \\
& =-\nabla \cdot \vec{Q}+\mathrm{ET}-P-\varepsilon
\end{aligned}
$$

where $\frac{d W}{d t}$ is the total change in precipitable water or atmospheric storage water ( $\mathrm{W}$ in $\mathrm{mm}$ ), IN and OUT are the lateral inflow and lateral outflow of water vapor flux across the lateral boundaries of the MSS, respectively, and $-\nabla \cdot \vec{Q}=\mathrm{IN}-$ OUT is the mean convergence of lateral atmospheric vapor flux in millimeter per day. The atmospheric vapor flux is computed from vertically integrated moisture fluxes taking note on the horizontal water vapor fluxes, specific humidity winds (meridional and zonal), and surface pressure. Related explanation of this calculation is available in the work of Roberts and Snelgrove (2015). $\varepsilon$ is the AWB residue or imbalance. The imbalance arises since Numerical Weather Prediction (NWP)-derived balances do not close (Draper and Mills 2008). Schär et al. (1999) noted that $\varepsilon$ can be distributed equally among the atmospheric fluxes, i.e., $\mathrm{IN}^{\text {corr }}=\mathrm{IN}=\varepsilon / 2$ andOUT ${ }^{\text {corr }}=\mathrm{OUT}+\varepsilon / 2$ in order for the atmospheric fluxes to satisfy the balance constraints.

Therefore,

$-\nabla \cdot \vec{Q}^{\mathrm{corr}}=\mathrm{IN}^{\mathrm{corr}}-\mathrm{OUT}^{\mathrm{corr}}$

where the superscript "corr" means corrected fluxes.

We denote $C=-\nabla \cdot \vec{Q}^{\text {corr }}$ (e.g., Yeh et al. 1998) in all subsequent discussions.

Equation ((2)) thus becomes

$\frac{d W}{d t}=C+\mathrm{ET}-P$

Two AWB measures that quantify the land-atmospheric interactions, relating $P$, ET, and $\mathrm{IN}$, are the recycling ratio $\beta$ and the precipitation efficiency $\chi$. They are defined here as derived by Schär et al. (1999) and mentioned in, e.g., Kunstmann and Jung (2007) and Asharaf et al. (2012) as

$\beta=\frac{\mathrm{ET}}{\mathrm{IN}+\mathrm{ET}}$

And

$X=\frac{P}{\mathrm{IN}+\mathrm{ET}}$

$\beta$ is the precipitation recycling ratio which refers to the fraction of precipitation in the study area that originates from evapotranspiration from the study area. $\chi$ is the precipitation efficiency which refers to the fraction of water that enters our study area (either by evapotranspiration or by atmospheric transport) and subsequently falls as precipitation. All the accompanying assumptions of these two measures otherwise referred to as bulk 
characteristics are considered to hold true for our analysis domain. As in the TWB components, all terms in AWB are spatially averaged over the study area that encompasses MSS.

\section{Results and discussion}

\subsection{Calibration of the uncoupled Weather Research and Forecasting-Hydro}

The uncoupled WRF-Hydro model consists of many parameters associated with large uncertainties. This may warrant for its calibration before application and analysis of its hydrological performance (Gochis et al. 2015). The meteorological forcing data to drive the uncoupled WRF-Hydro in calibration, for instance, included hourly incoming shortwave radiation (SWDOWN) and longwave radiation (LDOWN) measured in watt per square meter, specific humidity at 2-m height (Q2D) in kilogram per kilogram, air temperature at 2-m height (T2D) in Kelvin, surface pressure (PSFC) in Pascal, and near surface winds at 10-m height: $\mathrm{u}$ (U2D) and v (V2D) in meter per second. These datasets were extracted from WRF model output. The precipitation (RAINRATE) in millimeter per second was prepared from TRMM 3-hourly precipitation dataset. This was achieved through netcdf and climate data operator (NCO and CDO) algorithms.

The simulated discharge from the uncoupled WRF-Hydro model for the year 2012 is compared to that recorded at Tana Rukanga's RGS 4BE10. The year 2012 was chosen as it had a full record of discharge data. The year 2012 also showed a normal distribution of both seasonal and annual cycles of discharge more than all the other available years. One-year calibration is considered reasonably long enough to evaluate the basic parameter sensitivities.

Calibration procedure is motivated by the work of Yucel et al. (2015) who recommended a stepwise approach for this model to minimize the number of model runs and cut down excessive computational time. In the present study, four parameters are considered for calibration: the surface runoff parameter (REFKDT), surface retention depth scaling parameter (RETDEPRT), and overland flow roughness scaling parameter (OVROUGHRT) from the high-resolution terrain grid and the channel Manning roughness coefficient (MANN).

The REFKDT whose feasible range is $0.1-10$ with default value 3.0 controls the hydrograph volume. In our case, we considered the range 1.0-6.0. The RETDEPRTFAC whose default value is 1.0 has a similar function as REFKDT. We considered for our calibration the range 0.0-5.0. The OVROUGHRT and MANN control the hydrograph shape (Yucel et al. 2015). In our calibration, we took the ranges 0.0-1.0 and 0.4-2.0, respectively, for these two parameters. In the aforementioned order, the best value of REFKDT parameter obtained is fixed, while the RETDEPRTFAC is calibrated. The best values obtained at the two first steps are fixed in the subsequent calibration of the OVROUGHRTFAC. The obtained best values for the REFKDT, the RETDEPRTFAC, and the OVROUGHRTFAC are fixed in the calibration of the MANN. The best value for the MANN forms the end of our stepwise approach.

Table 3 shows the calibration results based on the selected objective criteria, i.e., the Nash-Sutcliffe efficiency (NSE) and the RMSE observation standard deviation ratio (RSR), between simulated and observed discharges at daily resolution for the entire year. Values of NSE are known to range between $-\infty$ and 1.0 ( 1 inclusive) with those between 0.0 and 1.0 considered acceptable (Moriasi et al. 2007). Lower RSR values mean low RMSE and, thus, better model simulation performance.

Figure 4 summarizes the calibration results, which show that the uncoupled WRF-Hydro reasonably reproduces the observed hydrograph over this catchment. In the overall calibration period, we got a NSE and RSR of 0.62 . The REFKDT $=2.0$, RETDEPRTFAC $=0.0$, OVROUGHRTFAC $=0.4$, and MANN scale factor $=1.8$ are considered to give the best results. The sensitivity of RETDEPRTFAC and OVOUGHRTFAC is, however, not as pronounced as that of REFKDT and MANN. The scaling factor of MANN $=1.8$ gives the calibrated manning coefficients in the range of 0.99 to 0.02 (Table 4). The RETDEPRTFAC $=0.0$ is in agreement with Yucel et al. (2015) who suggested that a value of zero for this parameter is ideal for steep slopes like that

Table 3 Selected objective criteria (Nash-Sutcliffe efficiency (NSE) and the RMSE observation standard deviation ratio (RSR)) between simulated and observed discharges at Tana Rukanga's RGS 4BE10 based on selected parameters: infiltration-runoff (REFKDT), retention (RETDEPRTFAC), overland flow roughness (OVROUGHRT), and the Manning's roughness coefficients (MANN) parameters

\begin{tabular}{clllllllll}
\hline REFKDT & & & & & & & & & \\
Range & 0.6 & 0.8 & 1.0 & 2.0 & 3.0 & 4.0 & 6.0 & & \\
RSR & 0.86 & 0.76 & 0.71 & 0.65 & 0.65 & 0.65 & 0.66 & & \\
NSE & 0.25 & 0.41 & 0.49 & 0.58 & 0.57 & 0.57 & 0.56 & & \\
RETDEPRTFAC & & & & & & & & \\
Range & 0.0 & 1.0 & 2.0 & 3.0 & 4.0 & 5.0 & & & \\
RSR & 0.65 & 0.65 & 0.65 & 0.65 & 0.65 & 0.65 & & & \\
NSE & 0.58 & 0.58 & 0.58 & 0.58 & 0.58 & 0.58 & & & \\
OVROUGHRTFAC & & & & & & & \\
Range & 0.1 & 0.2 & 0.4 & 0.6 & 0.8 & 1.0 & & & \\
RSR & 0.70 & 0.69 & 0.64 & 0.64 & 0.65 & 0.65 & & & \\
NSE & 0.51 & 0.53 & 0.59 & 0.58 & 0.58 & 0.58 & & & \\
MANN & & & & & & & & & \\
Range & 0.4 & 0.6 & 0.8 & 1.0 & 1.2 & 1.4 & 1.6 & 1.8 & 2.0 \\
RSR & 0.80 & 0.68 & 0.65 & 0.64 & 0.64 & 0.63 & 0.62 & 0.62 & 0.62 \\
NSE & 0.37 & 0.54 & 0.58 & 0.59 & 0.59 & 0.60 & 0.61 & 0.62 & 0.61 \\
\hline
\end{tabular}

Values in italics show the criteria for the selected parameters after calibration 


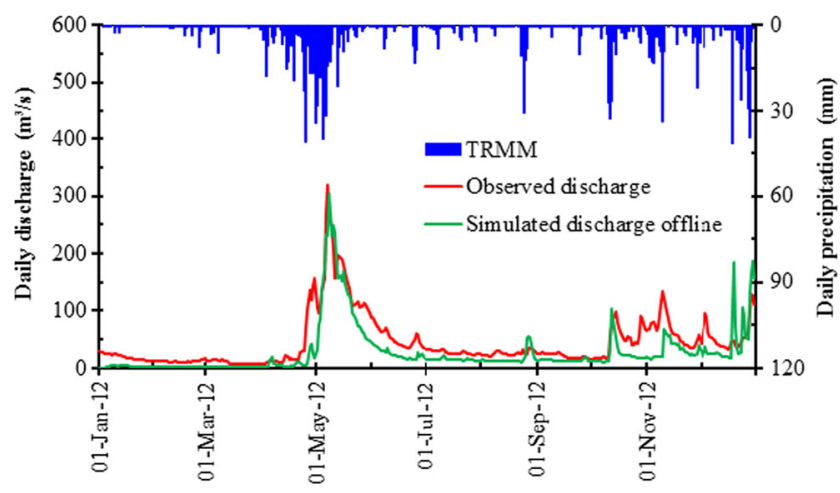

Fig. 4 Observed and simulated (uncoupled WRF-Hydro) hydrographs and derived precipitation from TRMM at Tana Rukanga's RGS 4BE10 for 2012. The year 2012 was considered for calibration

of MSS as there is no noticeable accumulation. Increases in the RETDEPRTFAC on channel pixels can encourage more local infiltration near the river channel leading to wetter soils (Gochis et al. 2015). This will not be necessarily associated with our case since this will reduce surface runoff further reducing the hydrograph volumes.

The model underestimates the observed discharge. For instance, at the end of the calibration process, the model is found to simulate only $60 \%$ of the observed discharge at the Tana Rukanga's RGS 4BE10 gauge at the end of the simulation period. But in general, the offline (uncoupled) WRF-Hydro is able to capture reasonably the dynamics of the hydrological regime of the MSS's streamflow. In all subsequent simulations, the calibrated parameters are held as such.

\subsection{Precipitation validation}

\subsubsection{Model results versus gridded data}

Prior to the analysis of the spatially averaged precipitation over the study area, the two models' seasonal mean

Table 4 Default channel parameter values of base width (Bw), initial water depth (HLINK), channel slope (ChSSlp), and the calibrated Manning coefficient (MannN) based on scaling factor 1.8 corresponding to each stream order

\begin{tabular}{lllll}
\hline Stream order & BW & HLINK & ChSSlp & MannN \\
\hline 1 & 1.5 & 0.02 & 3.0 & 0.55 \\
2 & 3.0 & 0.02 & 1.0 & 0.35 \\
3 & 5.0 & 0.02 & 0.5 & 0.15 \\
4 & 10 & 0.03 & 0.18 & 0.10 \\
5 & 20 & 0.03 & 0.05 & 0.07 \\
6 & 40 & 0.03 & 0.05 & 0.05 \\
7 & 60 & 0.03 & 0.05 & 0.04 \\
8 & 70 & 0.10 & 0.05 & 0.03 \\
9 & 80 & 0.30 & 0.05 & 0.02 \\
10 & 100 & 0.30 & 0.05 & 0.01 \\
\hline
\end{tabular}

precipitations in the inner domain are compared to those derived from CHIRPS. Figures 5 and 6 display the spatial maps of the MAM and OND seasonal precipitations as derived from CHIRPS and simulated in WRF-only and coupled WRFHydro. A common feature seen in the spatial maps is that the two models exhibit a similar pattern in either of the seasons. They both capture well the precipitation maximum in the vicinity of upper Tana River basin (TRB). Thus, a clear dependence of precipitation on topography is depicted. The difference between different years is evident though in general, the two models underestimate the MAM precipitation while they overestimate the OND precipitation especially in upper TRB. The relationship of both WRF-only and coupled WRFHydro to CHIRPS estimates is summarized in Fig. 7. Here, the normalized statistical comparison of the monthly sums of precipitation of all MAMs and all ONDs during 2011 to 2014 is shown. Both WRF-only and WRF-Hydro display similar spatial variability with fair to good pattern correlations $(r \geq 0.6)$ and normalized standard deviation close to that of the observations.

Spatially averaged precipitation over Mathioya-Sagana subcatchment The spatially averaged precipitation from WRF-only and coupled WRF-Hydro is compared against two observational datasets: TRMM and CHIRPS. Figure 8 shows the four monthly time series of both the simulated and observed precipitation. Both WRF-only and coupled WRF-Hydro capture quite reasonably the seasonal, annual, and interannual evolution of precipitation derived from CHIRPS and TRMM with overall high correlation coefficients $[r(46)>0.7, p<0.001]$. The two modeling systems capture well the seasonal peak of OND as November but occasionally miss that of the MAM season by 1 month.

Seasonal and cumulative totals over the study area Both models capture well the variability of the two rainy seasons, MAM and OND, over the MSS and surrounding area. The total seasonal simulated precipitation for the 4 years (2011 to 2014) is more than that derived from TRMM but slightly less than that derived from CHIRPS. The respective mean annual precipitations (i.e., for the two seasons only) are TRMM = $795 \mathrm{~mm} /$ year, CHIRPS = $989 \mathrm{~mm} /$ year, WRF-only $=977 \mathrm{~mm} /$ year, and WRF-Hydro = $940 \mathrm{~mm} /$ year showing a reasonable agreement but more so with CHIRPS dataset (Table 5). During MAM, the models underestimate the observed precipitation in both TRMM and CHIRPS in 2011 and 2012. The simulated amount is slightly closer to that derived in CHIRPS in 2013. In OND, it is seen that both WRFonly and WRF-Hydro overestimate the observed precipitation in the two datasets (Fig. 9a). In terms of the cumulative precipitation, WRF-only (1392 mm/year) and coupled WRFHydro (1318 mm) yielded more precipitation compared to that derived in TRMM (1092 mm) in excess of approximately 27 
Fig. 5 Precipitation maps for the inner domain D2, averaged for the March, April, and May (MAM) season for the period 2011 to 2014, derived from a CHIRPS, and the two modeling systems: $\mathbf{b}$ WRF-only and coupled WRFHydro. The red contour delineates part of the TRB
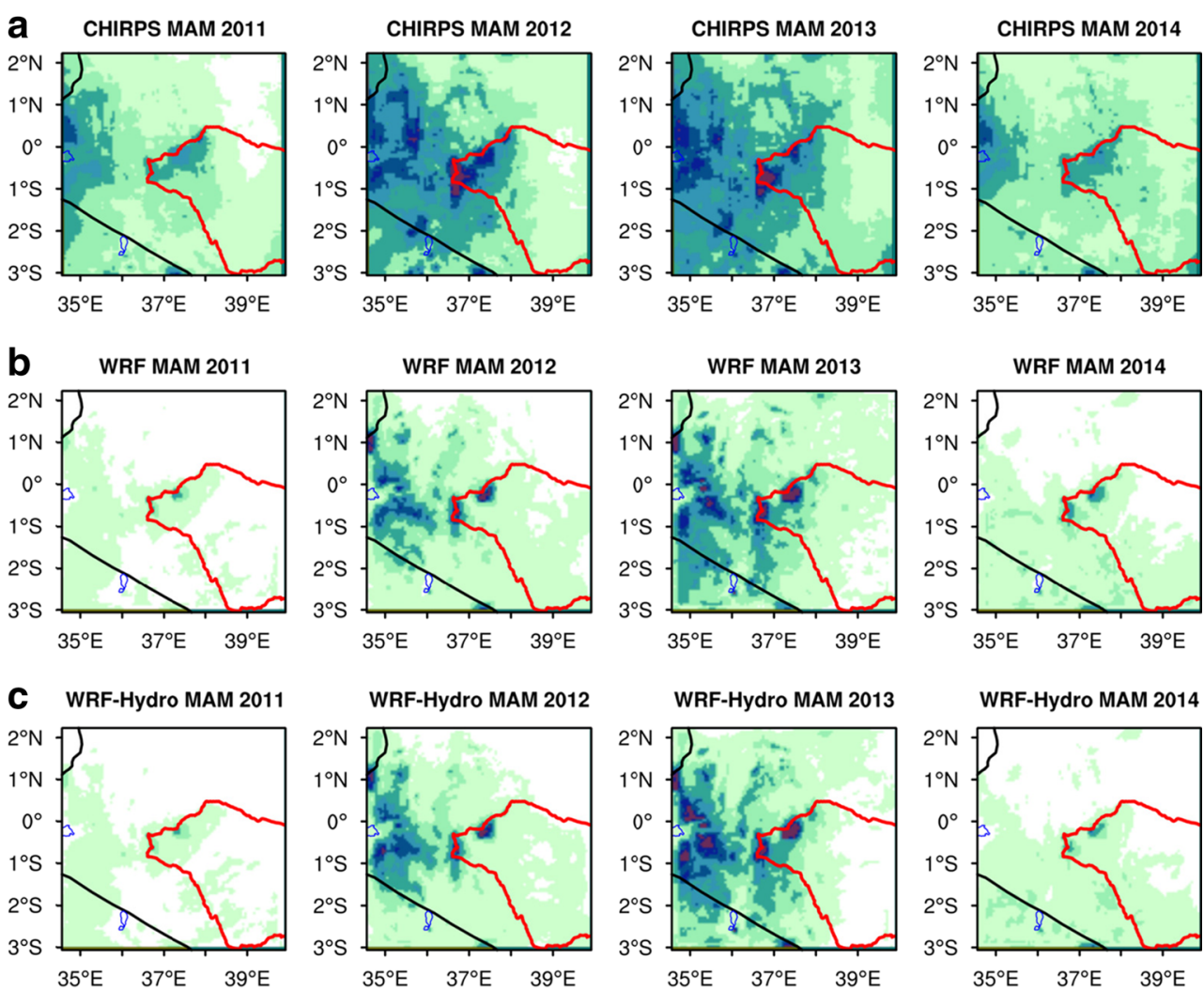

and $21 \%$, respectively (Table 5). This is not the case compared to the total cumulative precipitation derived from CHIRPS (1352 $\mathrm{mm})$, whereby there is a closer agreement in the cumulative totals for both WRF-only and WRF-Hydro with same magnitude of excess and deficiency of $2 \%$ (Fig. 9b). It is also seen that the coupled WRF-Hydro simulates slightly less precipitation compared to WRF-only consistent with early studies (e.g., Senatore et al. 2015).

\subsubsection{Model results versus station data}

The precipitations from the three stations (Nyeri, Murang'a, Sagana) over the MSS are compared to those derived from the corresponding WRF-only and coupled WRF-Hydro grid points. The precipitation amounts are all mean centered, i.e., subtracting each value from the mean of the respective series. Figure 10 shows the resulting scatter plots. There is a fair agreement between the shape of the monthly series: the simulated (WRF-only; coupled WRF-Hydro) and the observed (station data). This is an indication of the two modeling systems capturing fairly well the seasonal and annual evolution of precipitation in this region. Both the coupled WRF-Hydro and WRF-only explain the variability of station data in a similar manner. Further examination of the skill scores (SS) of the two models averaging over all the stations shows that WRF-only exhibits a lower SS of 0.01 than WRF-Hydro $(\mathrm{SS} \approx 0.09$ ). Note that the SS are constructed using either mean absolute error (MAE), mean square error (MSE), or the root-meansquare error (RMSE). Just as the NSE, they range between $-\infty$ and +1 . This shows that coupled WRF-Hydro has slightly better skill in estimating the station data than WRF-only. Table 6 confirms the previous results, although it is clear that the two models underestimate the station precipitation. This is consistent with the results discussed in Sect. 3.2.1.

\subsection{River discharge}

The coupled WRF-Hydro simulated river discharge is compared to that observed at Tana Rukanga's RGS 4BE10 for 2011 to 2014. Figure 11 shows the hydrograph of observed and simulated discharges at a daily resolution and the corresponding precipitation as simulated from coupled WRFHydro over the MSS during 2011 to 2014. The simulated and observed discharges for the entire period (2011 to 2014) are fairly correlated with correlation coefficient, $r$ (1386) $\approx 0.52, p<0.001$, with, however, occasional lagging 
Fig. 6 As in Fig. 5, except for the October, November, and December (OND) season
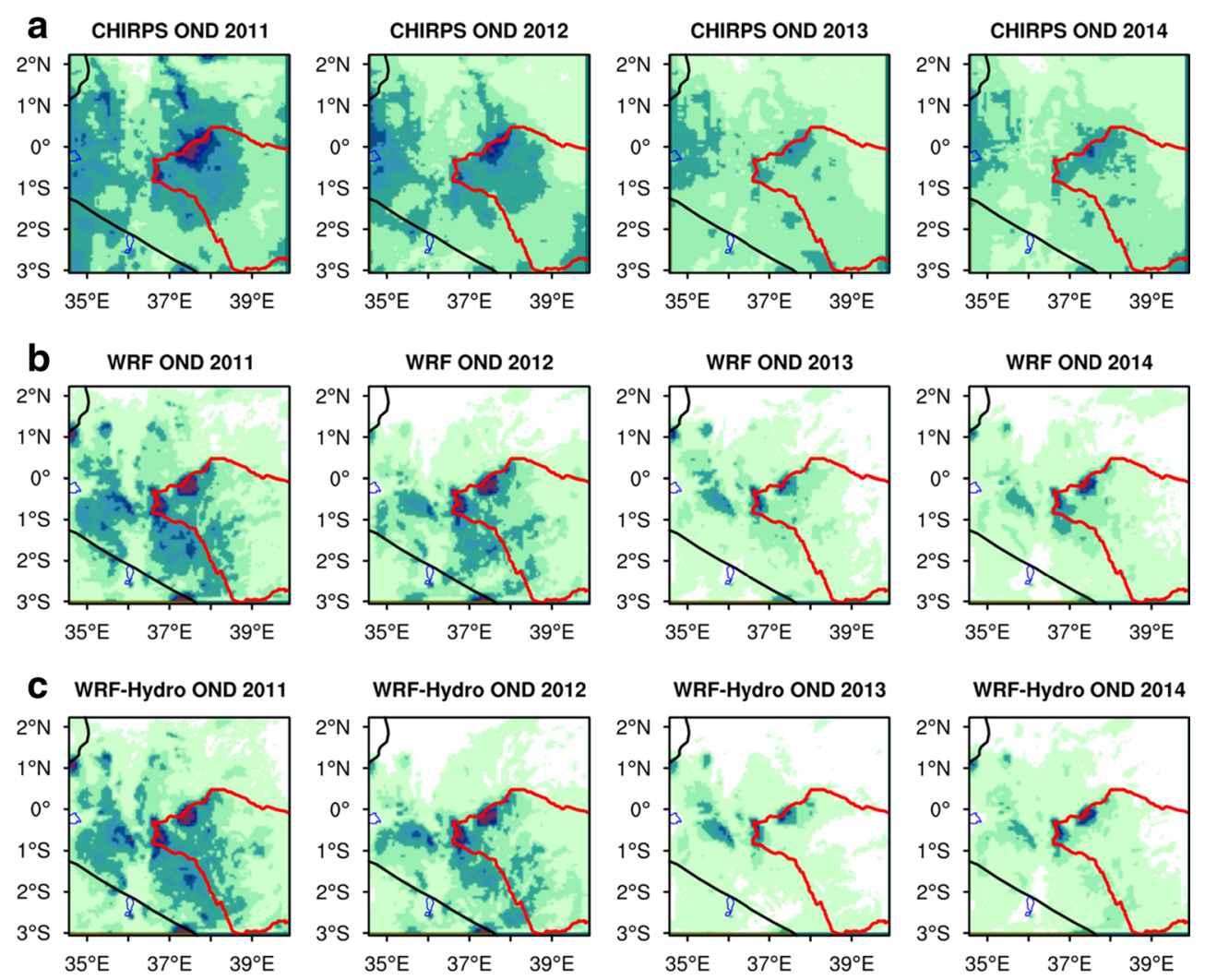

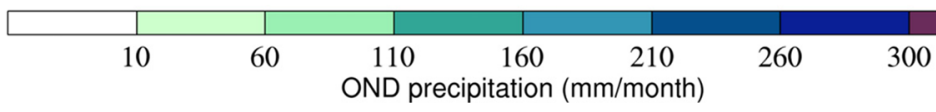

of simulated peaks to those observed. There is a clear correspondence of the observed and simulated discharges as a

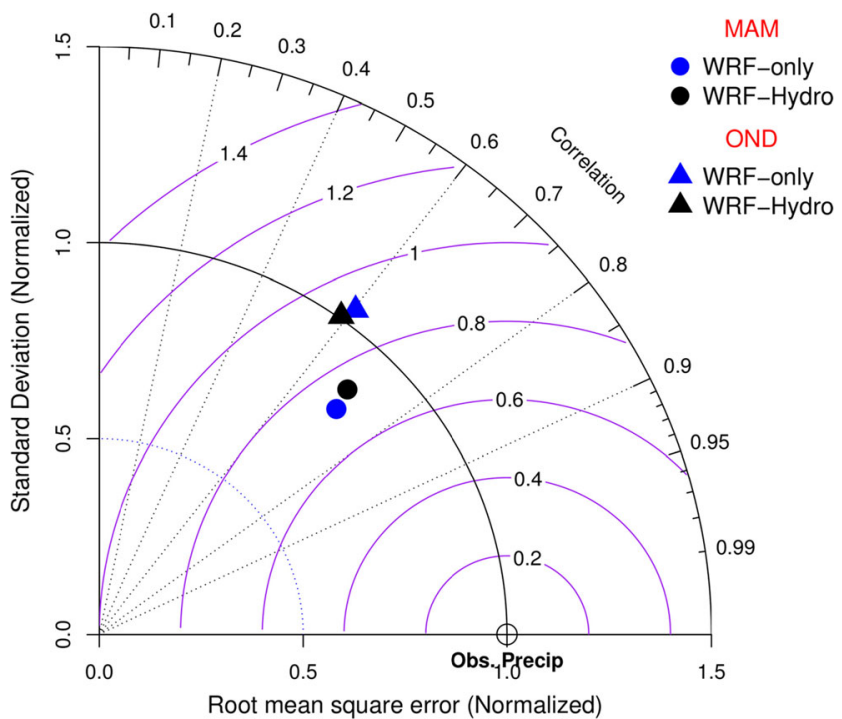

Fig. 7 Taylor diagram showing normalized pattern statistics of monthly precipitation sums for MAM and OND seasons between WRF-only/ coupled WRF-Hydro simulations and CHIRPS estimates over domain D2, for the period 2011 to 2014 response to the rainstorms in the region. This is demonstrated in a linear relationship between discharge and precipitation over the catchment (correlation coefficient of 0.81 ). The derived statistics from the simulated and observed series are shown in Table 7 . The model reasonably captures the high flows of May, 2013, and those of OND season. The best performance is obtained for the year 2013.

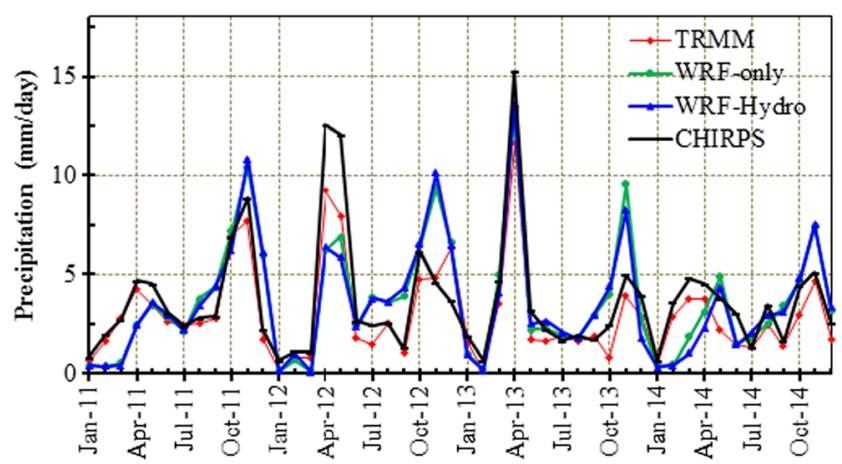

Fig. 8 Time series of monthly precipitation (in $\mathrm{mm} /$ day) spatially averaged over the Mathioya-Sagana subcatchment (MSS) and surrounding area (see Fig. 1) derived from TRMM, CHIRPS, WRF-only, and coupled WRF-Hydro 
Table 5 Selected statistics (mean absolute error (MAE), root mean square error (RMSE), correlation coefficient $(r)$, and the percent bias (Pbias)) between simulated WRF-only and coupled WRFHydro and derived precipitation from TRMM and CHIRPS spatially averaged over the Mathioya-Sagana subacatchment (MSS) and surrounding area for the period 2011 to 2014

\begin{tabular}{llllll}
\hline & Experiment & MAE (mm/day) & RMSE (mm/day) & $r$ & Pbias (\%) \\
\hline TRMM & WRF-only & 1.4 & 1.9 & 0.8 & 23.1 \\
& WRF-Hydro & 1.5 & 2 & 0.77 & 20.5 \\
CHIRPS & WRF-only & 1.5 & 2.1 & 0.75 & -0.6 \\
& WRF-Hydro & 1.6 & 2.2 & 0.73 & -2.7 \\
Total precipitation (mm/year) & & & & \\
TRMM & 1092 & & & & \\
CHIRPS & 1352 & & & & \\
WRF-only & 1392 & & & & \\
WRF-Hydro & 1318 & &
\end{tabular}

The averaged discharge observed at RGS 4BE10 during this period was $36.0 \mathrm{~m}^{3} / \mathrm{s}$ (or $346 \mathrm{~mm} /$ year), while the corresponding simulated discharge is approximately $34.7 \mathrm{~m}^{3} / \mathrm{s}$ (or $334 \mathrm{~mm} /$ year), i.e. only approximately $3 \%$ difference. The corresponding values for precipitation in the delineated MSS are simulated $=988 \mathrm{~mm} /$ year, observed precipitation in CHIRPS $=1263 \mathrm{~mm} /$ year, and in TRMM $=1059 \mathrm{~mm} /$ year. This gives a discharge-precipitation coefficient between 0.26 and 0.33 for the observational datasets considered and 0.34 for the simulation.

The low and even negative NSE of simulated discharge for some years has also been achieved in neighboring basins (e.g., Mango et al. 2011; Obiero 2011). There are also differences in
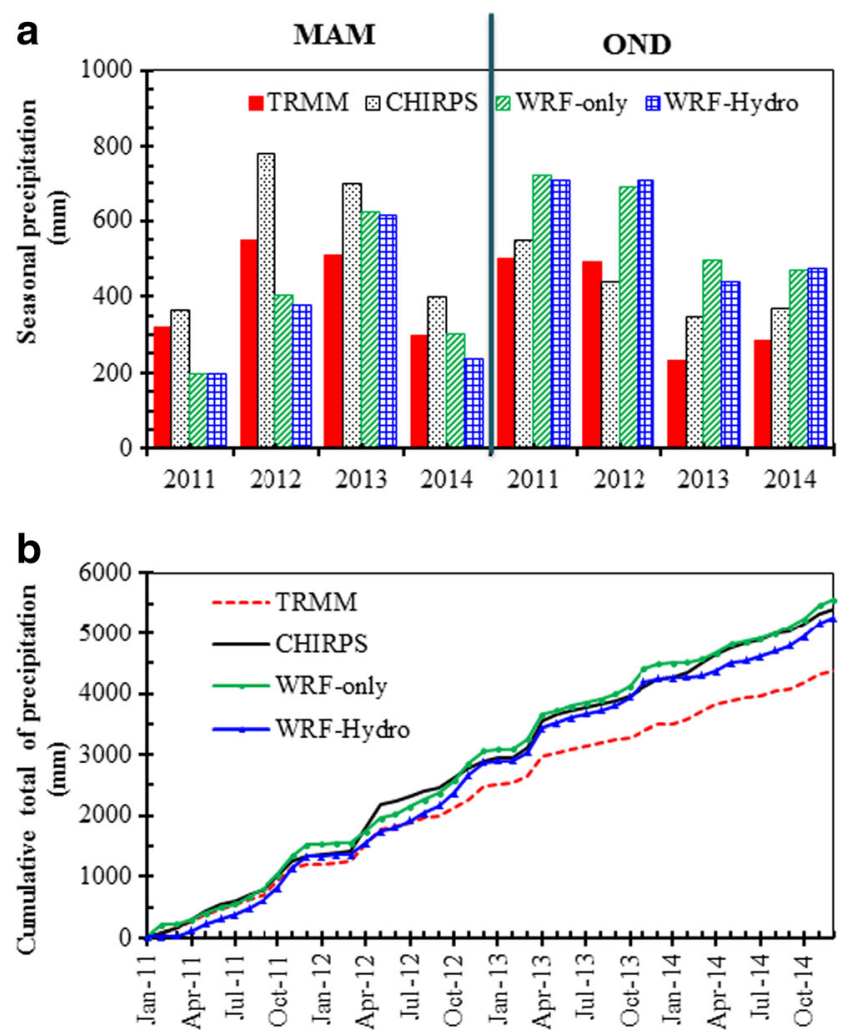

Fig. 9 a As in Fig. 8, except for seasonal (MAM and OND) and b cumulative precipitation the performance between the uncoupled WRF-Hydro model in calibration and the coupled WRF-Hydro, perhaps partially due to the different frequency that the Noah LSM is called in the offline calibration and during the coupled runs (Senatore et al. 2015). Besides, this may be attributed to the different forcing data that drives the coupled and uncoupled WRFHydro modeling systems. Though, in general, the coupled WRF-Hydro just like in its uncoupled mode captures reasonably the hydrological dynamics of the basin.

\subsection{Water balance results}

\subsubsection{Terrestrial water balance}

This section is based on the theory given in Sect. 2.4.1. The seasonal and interannual variation of precipitation $(P)$,

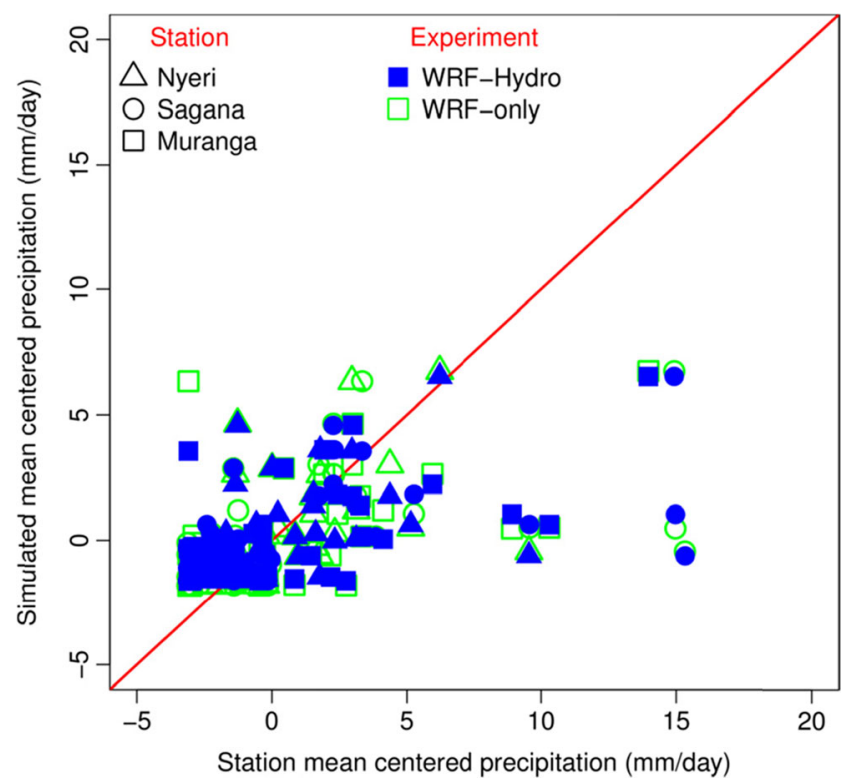

Fig. 10 Scatter plot between mean-centered monthly precipitation time series from the simulations (WRF-only, coupled WRF-Hydro) and station measurements at Nyeri, Sagana, and Murang'a for 2011 to 2014. The correlation coefficients refer to each station in the order: Nyeri, Sagana, and Murang'a, respectively 
Table 6 As in Table 5 but between nearest grid point of WRF/WRF-Hydro and observed stations' (Nyeri, Sagana, Murang'a) precipitation for the period 2011 to 2014

\begin{tabular}{|c|c|c|c|c|c|c|}
\hline & & Experiment & $\operatorname{MAE}(\mathrm{mm} /$ day $)$ & RMSE (mm/day) & $r$ & Pbias (\%) \\
\hline \multirow[t]{2}{*}{ Nyeri } & & WRF-only & 1.4 & 2.3 & 0.52 & -27.3 \\
\hline & & WRF-Hydro & 1.5 & 2.4 & 0.46 & -35.1 \\
\hline \multirow[t]{2}{*}{ Sagana } & & WRF-only & 2.2 & 4.2 & 0.53 & -41.8 \\
\hline & & WRF-Hydro & 2.2 & 4.2 & 0.56 & -48.0 \\
\hline \multirow[t]{3}{*}{ Murang'a } & & WRF-only & 2.1 & 3.4 & 0.56 & -41.2 \\
\hline & & WRF-Hydro & 2.1 & 3.4 & 0.61 & -47.4 \\
\hline & Total precipitation ( $\mathrm{m}$ & & & & & \\
\hline \multirow[t]{3}{*}{ Nyeri } & Observed & 917 & & & & \\
\hline & WRF-only & 436 & & & & \\
\hline & WRF-Hydro & 407 & & & & \\
\hline \multirow[t]{3}{*}{ Sagana } & Observed & 1140 & & & & \\
\hline & WRF-only & 605 & & & & \\
\hline & WRF-Hydro & 501 & & & & \\
\hline \multirow[t]{3}{*}{ Murang'a } & Observed & 1127 & & & & \\
\hline & WRF-only & 632 & & & & \\
\hline & WRF-Hydro & 551 & & & & \\
\hline WRF-only & Common grid point & 668 & & & & \\
\hline WRF-Hydro & Common grid point & 594 & & & & \\
\hline
\end{tabular}

The total precipitation for the whole period is also provided

evapotranspiration (ET), discharge $(R)$, and change in terrestrial water storage $(d S / d t)$ over the MSS is presented here. The terrestrial water balance (TWB) components in this study are processed from the WRF-only and coupled WRF-Hydro modeling system. $P$, ET, and $R$ are directly derived from the model outputs, while $d S / d t$ is calculated as a residue, i.e., $d S /$ $d t=P-(\mathrm{ET}+R)$. Table 8 and Figure 12 show the seasonal and interannual variability of these TWB components simulated by WRF-only and coupled WRF-Hydro and are discussed in the following subsections.

Precipitation The monthly evolution and interannual variability of $P$ for both WRF-only and coupled WRF-Hydro

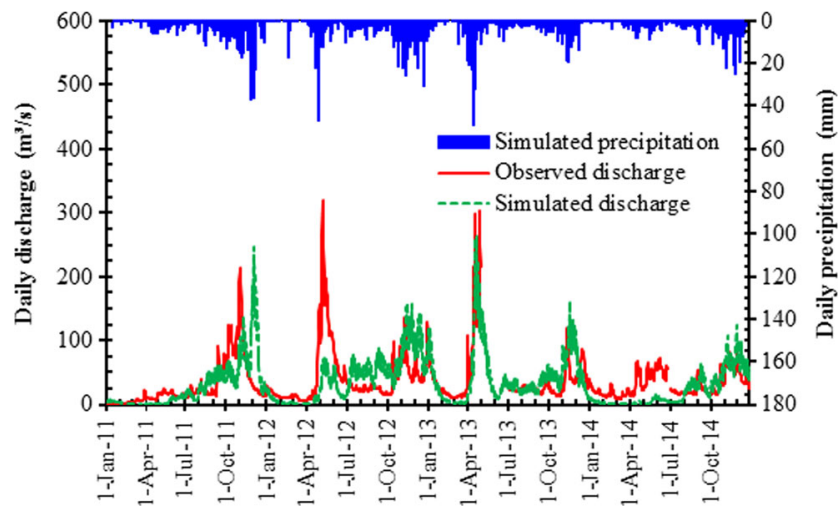

Fig. 11 Observed and simulated (coupled WRF-Hydro) hydrographs and precipitation in the Mathioya-Sagana subcatchment (MSS) for the period 2011 to 2014 at Tana Rukanga's RGS 4BE10 exhibit striking similarity (see Sect. 3.2). For the period 2011 to 2014, WRF-only yields an average of $3.7 \mathrm{~mm} /$ day, while coupled WRF-Hydro yields slightly less, i.e., $3.6 \mathrm{~mm} /$ day.

Discharge Simulated discharge in the coupled WRF-Hydro and total runoff from WRF-only show similar seasonality and interannual variability. Both WRF-only and coupled WRFHydro indicate April as the peak month for the AMJ season, while they indicate November as the peak month for the OND season. The April peak comes slightly earlier than the climatological peak of May. However, this shows a very close relationship with $P$. The 4-year (2011 to 2014) average is $0.90 \mathrm{~mm} /$ day for WRF-only, while in the case of coupled

Table 7 Selected objective criteria as in Table 3 but between simulated coupled WRF-Hydro discharge and that recorded at the 4BE10 gauge for the period 2011 to 2014

\begin{tabular}{|c|c|c|c|c|c|}
\hline & 2011-2014 & 2011 & 2012 & 2013 & 2014 \\
\hline \multicolumn{6}{|c|}{ Daily time step } \\
\hline NSE & 0.02 & -0.17 & -0.21 & 0.49 & -1.02 \\
\hline RSR & 0.99 & 1.08 & 1.10 & 0.71 & 1.42 \\
\hline \multicolumn{6}{|c|}{ Monthly time step } \\
\hline NSE & 0.15 & 0.35 & -0.85 & 0.71 & -1.43 \\
\hline RSR & 0.91 & 0.77 & 1.30 & 0.51 & 1.49 \\
\hline
\end{tabular}


Table 8 Annual averages of the atmospheric and terrestrial water balance components (AWB and TWB) (mm/day) from Eqs. 1 and (4), as simulated in WRF-only and coupled WRF-Hydro for Mathioya-Sagana subcatchment and surrounding areas during 2011 to 2014

\begin{tabular}{|c|c|c|c|c|c|c|c|}
\hline & Experiment & & 2011 & 2012 & 2013 & 2014 & 4-year mean \\
\hline \multirow[t]{2}{*}{$d W / d t$} & WRF-only & AWB & 0.00 & 0.01 & 0.00 & -0.01 & 0.00 \\
\hline & WRF-Hydro & TWB & 00.0 & 0.02 & 0.00 & -0.01 & 0.00 \\
\hline \multirow[t]{2}{*}{$d S / d t$} & WRF-only & TWB & 1.00 & 0.94 & 0.46 & 0.48 & 0.72 \\
\hline & WRF-Hydro & TWB & 1.07 & 0.90 & 0.26 & 0.47 & 0.68 \\
\hline \multirow[t]{2}{*}{ IN } & WRF-only & AWB & 118.50 & 118.80 & 119.98 & 122.18 & 119.86 \\
\hline & WRF-Hydro & AWB & 117.99 & 117.28 & 117.73 & 120.87 & 118.87 \\
\hline \multirow[t]{2}{*}{ OUT } & WRF-only & AWB & 117.14 & 117.28 & 118.87 & 121.60 & 118.72 \\
\hline & WRF-Hydro & AWB & 116.72 & 117.30 & 116.75 & 120.27 & 117.76 \\
\hline \multirow[t]{2}{*}{ C } & WRF-only & AWB & 1.36 & 1.52 & 1.11 & 0.58 & 1.14 \\
\hline & WRF-Hydro & AWB & 1.27 & 1.59 & 0.98 & 0.60 & 1.11 \\
\hline \multirow[t]{4}{*}{$P$} & WRF-only & AWB & 3.14 & 3.71 & 3.41 & 2.51 & 3.19 \\
\hline & & TWB & 3.67 & 4.19 & 3.91 & 2.94 & 3.68 \\
\hline & WRF-Hydro & AWB & 3.06 & 3.75 & 3.27 & 2.32 & 3.10 \\
\hline & & TWB & 3.62 & 4.22 & 3.77 & 2.80 & 3.60 \\
\hline \multirow[t]{4}{*}{ ET } & WRF-only & AWB & 1.79 & 2.21 & 2.31 & 1.92 & 2.06 \\
\hline & & TWB & 1.78 & 2.17 & 2.30 & 1.93 & 2.06 \\
\hline & WRF-Hydro & AWB & 1.79 & 2.17 & 2.30 & 1.72 & 1.99 \\
\hline & & TWB & 1.78 & 2.17 & 2.30 & 1.73 & 2.00 \\
\hline \multirow[t]{2}{*}{$R$} & WRF-only & TWB & 0.87 & 1.05 & 1.14 & 0.53 & 0.90 \\
\hline & WRF-Hydro & TWB & 0.77 & 1.14 & 1.22 & 0.60 & 0.93 \\
\hline
\end{tabular}

WRF-Hydro, it is slightly higher, i.e., $0.93 \mathrm{~mm} /$ day. This is also close to that observed which is, on average, $0.95 \mathrm{~mm} /$ day. In terms of monthly evolution, WRF-only series was found to correlate to that of observed fairly $(r \approx 0.68, p<001)$ compared to WRF-Hydro $(r \approx 0.62, p<0.001)$. The performance in 2011 shows that the coupled WRF-Hydro yields less runoff than WRF-only as expected owing to lateral soil water redistribution that leads to higher water storage in the soil. This is not the case for the other years, i.e., 2012, 2013, and 2014, which determines the mean performance of coupled WRFHydro and WRF-only to be different from expectations. This can be attributed to a large contribution of exfiltration due to the high elevation in MSS. In this regard, the coupled WRF-Hydro decreases surface runoff by allowing surface water to infiltrate at different time steps at different locations on one hand and on the other hand allowing exfiltration, which increases surface runoff.

Evapotranspiration The monthly and interannual variation of ET as simulated by WRF-only and coupled WRF-Hydro is equally similar. The 4-year average for WRF-only is $2.2 \mathrm{~mm} /$ day and that of coupled WRF-Hydro is $2.1 \mathrm{~mm} /$ day, i.e., slightly less. ET displays small monthly variation throughout the period of 2011 to 2014. Lowest values occur during the months of March and August, while the peak months with highest values fall during the months of April and December-January. During the peak season of ET, the plants and environment transfer large quantities of water vapor into the atmosphere recovered from the immediate rainy season.

Change in terrestrial water storage The monthly evolution and interannual evolution of $d S / d t$ exhibit seasonality with peak values in the months of April and November. The 4year average value of $d S / d t$ derived from WRF-only is $0.72 \mathrm{~mm} /$ day compared to that from coupled WRF-Hydro of $0.68 \mathrm{~mm} /$ day. This is consistent with a reduction of precipitation and increase of runoff in coupled WRF-Hydro, in comparison to WRF-only. On the monthly scale, $d S / d t$ displays both negative values and positive values. The negative or low values are dominant during the months of JanuaryFebruary and June. Both models exhibit similar interannual variability.

Relationship between Weather Research and Forecastingonly and coupled Weather Research and ForecastingHydro terrestrial water balance components The monthly differences between the TWB components as simulated by the two models are shown in Fig. 13. The magnitudes of the average differences for all TWB components are very small (between 0.03 and $0.08 \mathrm{~mm} /$ day). Precipitation shows the highest magnitude, while discharge shows the least. It is only in the simulated discharge that coupled WRF-Hydro yields more than the WRF-only model. 

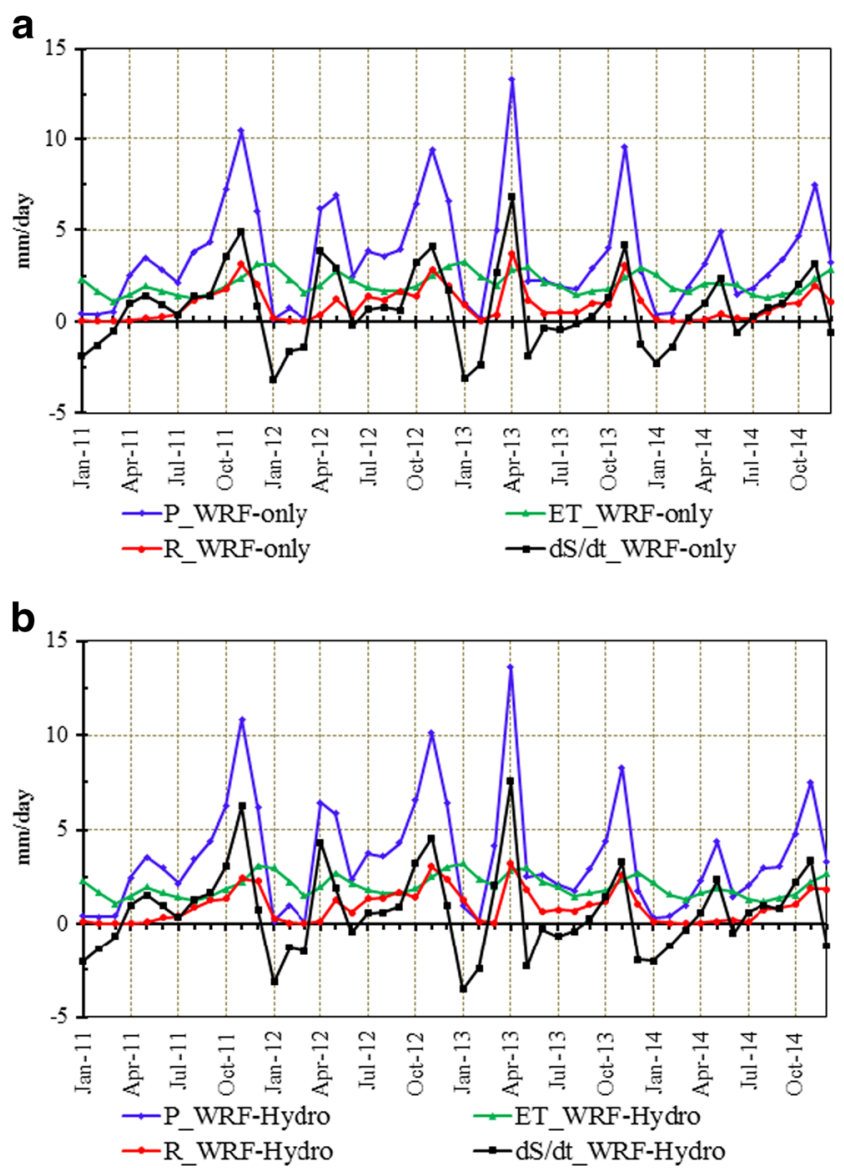

Fig. 12 Monthly time series of the terrestrial water balance (TWB) components (Eq. 1) in millimeter per day, as simulated in a WRF-only and $\mathbf{b}$ coupled WRF-Hydro, averaged over the Mathioya-Sagana subcatchment (MSS) and surrounding area (see Fig. 1) for the period 2011 to 2014

The evolution of monthly differences in $d S / d t$ and $P$ in both models shows similar patterns with higher differences in the peak months of the MAM and OND seasons. On average, the differences for all TWB components are minimal and constant during the dry months of June to October. This shows that in the absence of $P$ and ET differences between WRF-only and WRF-Hydro, differences in the other components are equally insignificant. In the case of $d S / d t$ and $R$, the sign of the

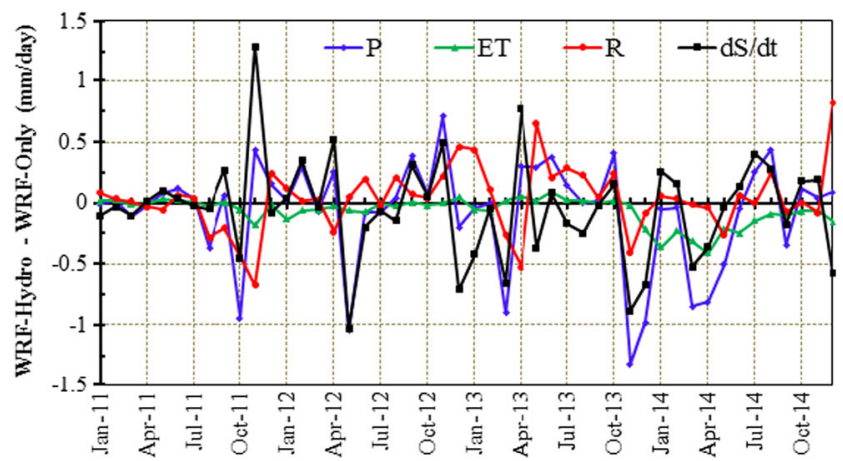

Fig. 13 As in Fig. 12, except for the difference between WRF-only and WRF-Hydro (coupled WRF-Hydro minus WRF-only) differences often alternates; i.e., increased (reduced) runoff leads to lowering (increasing) of the amount of soil moisture. This is common during the peak months of the rainy seasons of MAM and OND.

The annual difference $P$ - ET for the two models yields same values (Table 8). On average, these differences are $1.6 \mathrm{~mm} /$ day. On the other hand, the annual difference $P-R$ for WRF-only is $2.8 \mathrm{~mm} /$ day and that for coupled WRFHydro is $2.7 \mathrm{~mm} /$ day. This shows that there is more abundance of soil recharge in this area according to WRF-only than coupled WRF-Hydro. However, in the months of January to March, there is a soil deficit as ET $>P$ (Fig. 13). This is an indication that evapotranspiration is more critical during these months than during the rainy seasons.

\subsubsection{Atmospheric water balance}

The basic theory of the atmospheric water balance (AWB) is presented in Sect. 2.4.2. All the variables are averaged over a rectangular boundary encompassing the Mathioya-Sagana subcatchment (MSS). The simulated variables from the WRF-only and coupled WRF-Hydro models for the 4-year
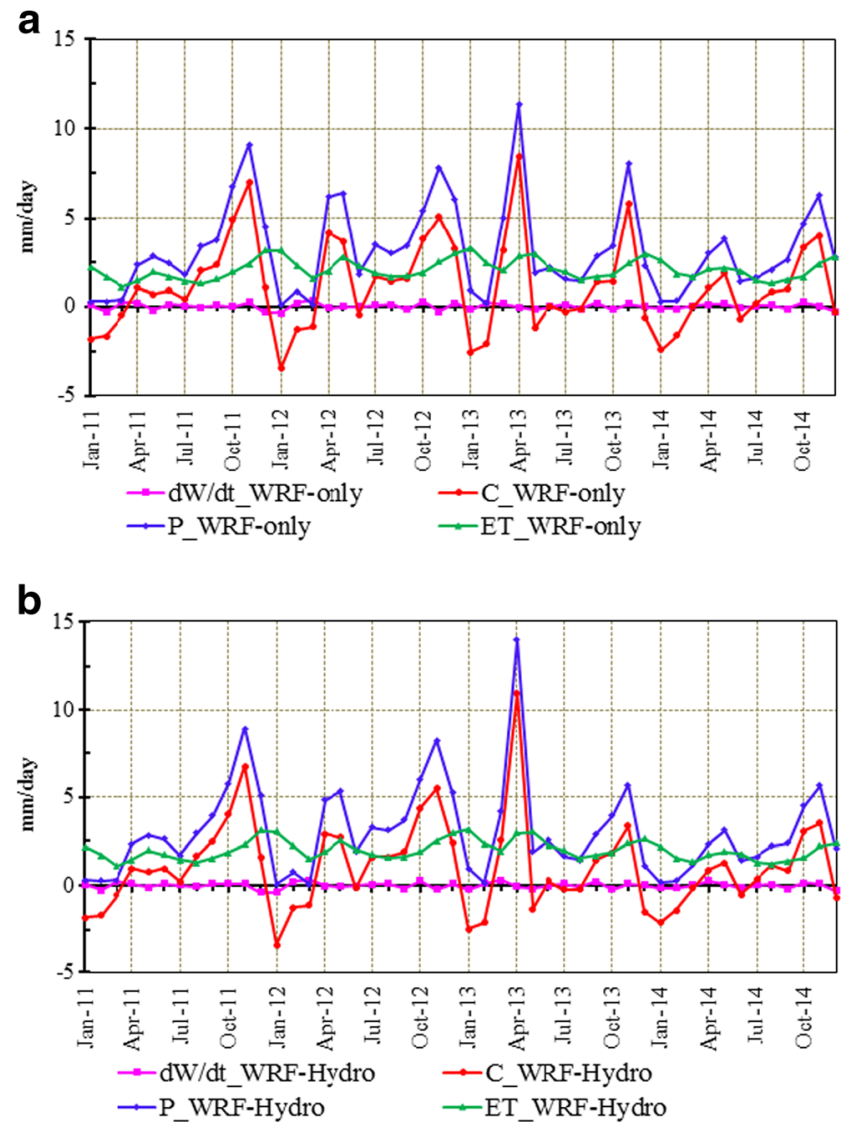

Fig. 14 As in Fig. 12, except for the monthly atmospheric water balance (AWB) components (Eq. (4)) 


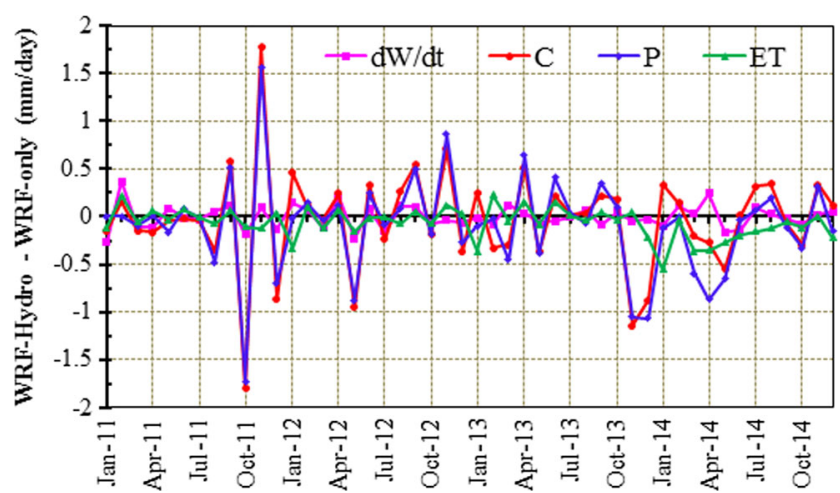

Fig. 15 As in Fig. 14, except for the difference between WRF-only and WRF-Hydro (coupled WRF-Hydro minus WRF-only)

(2011 to 2014) climatology are displayed in Table 8 and Figs. 14 and 15 and discussed in this section.

Precipitation and evapotranspiration The monthly and interannual variation of $P$ and ET has been discussed in Sect. 3.4.1 for the TWB. $P$ is considered a loss from the atmosphere and a gain for the terrestrial surface, while ET is obviously a gain for the atmosphere and a loss from the surface. ET reaches its peak in May for the MAM season, 1 month after that of $P$.

Atmospheric moisture convergence The atmospheric moisture convergence $C$ monthly and interannual variation follows that of precipitation. $C$ reaches its peak in April and November, which are the peak months of the two rainy seasons (i.e., MAM and OND) in this region. The lowest values are during the months of January.

Atmospheric water storage The atmospheric water storage, $d W / d t$, hardly shows any monthly or interannual variation in both WRF-only and coupled WRF-Hydro. It is very small compared to the other terms and tends to zero, as expected for a regional water balance.

\section{Relationship between Weather Research and Forecasting- only and coupled Weather Research and Forecasting- Hydro components The monthly differences between}

coupled WRF-Hydro and WRF-only AWB components are summarized and displayed in Fig. 15. The differences in $P$ and $\mathrm{C}$ display a similar pattern over the years. This implies that the differences in $P$ originate from differences in $\mathrm{C}$. This is associated with the impact of moisture vapor influx into the domain whose average magnitude for the 4-year period is greater than that of vapor outflow in both models. However, in individual years, the models display larger differences, especially during the years when the coupled WRF-Hydro yields more C than WRF-only model. The differences in ET and dW/dt are comparatively smaller with, however, the year 2014 having the highest difference for the case of ET $(0.20 \mathrm{~mm} /$ day $)$.

\subsection{Land-atmospheric interactions within Mathioya-Sagana subcatchment}

This section is based on Eqs. 5 and 6 mentioned in Sect. 2.4.2 on the atmospheric bulky properties, i.e., the recycling ratio $\beta$ and the precipitation efficiency $\chi$. The two measures are used to analyze the land-atmospheric interactions and feedback between the land and atmosphere in the study area.

Recycling ratio $\boldsymbol{\beta}$ Figure 16a shows the mean annual cycle of the recycling ratio $\beta$ for the period 2011 to 2014 as simulated in the WRF-only and coupled WRF-Hydro. In general, the value of $\beta$ is high whenever there are low moisture influx and high evapotranspiration (e.g., Asharaf et al. 2012). $\beta$ is seen to vary from 0.01 to 0.04 . High values of $\beta$ occur during the months of January that exhibit largest amount of ET (dominant compared to $P$ ). In terms of the rainy seasons, i.e., MAM and OND, it is noticed that $\beta$ remains below 0.02 . This implies that precipitation originating from evapotranspiration in the MSS region, i.e., the study area, contributes little to total precipitation in this region during the quadrennial. It is concluded that local precipitation in the MSS region does not depend significantly on the state of the land surface and that potential land-precipitation feedback mechanisms have a reduced impact in this region.

Precipitation efficiency $\chi$ The mean annual cycle of the precipitation efficiency $\chi$ is displayed in Fig. 16b. Two distinct
Fig. 16 Mean annual cycle of a recycling ratio and $\mathbf{b}$ precipitation efficiency as simulated in WRFonly and coupled WRF-Hydro over the MSS and surrounding area (Fig. 1) for the years 2011 to 2014
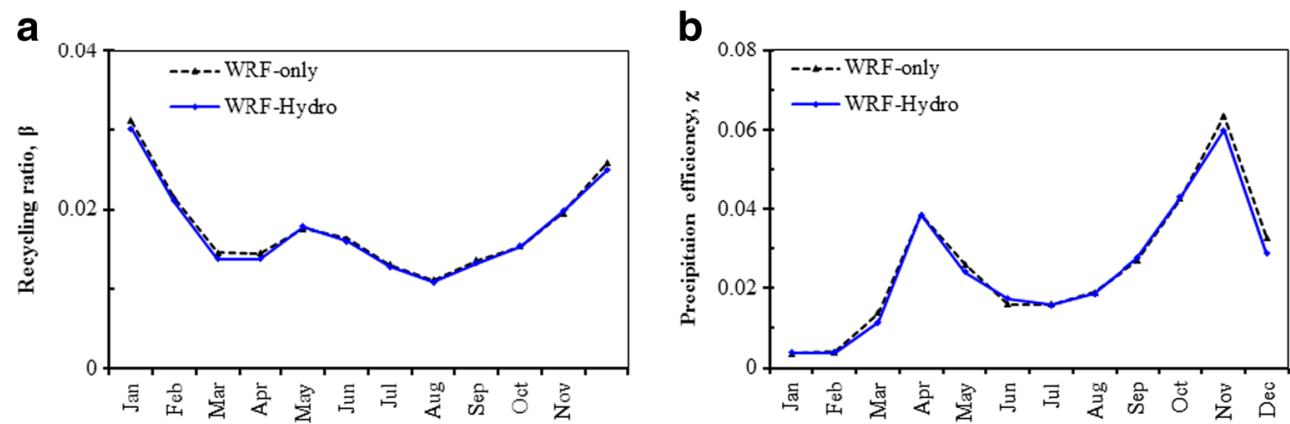
seasons similar to those of the rainy seasons, i.e., MAM and OND, are depicted. The values of $\chi$ for the two models are in the range of 0.0 and 0.07 and reach their peaks during the months of April and November. Low $\chi$ further implies that only a small portion of the atmospheric water inflow does contribute to most of the precipitation in the MSS region.

\section{Summary and conclusion}

The hydrometeorology of the Mathioya-Sagana subcatchment (MSS) and its surrounding in the upper Tana River basin (TRB), Kenya, East Africa, has been investigated in terms of its terrestrial and AWB components. This has been achieved through the application of the coupled WRF-Hydro modeling system whose results have been compared to the WRF-only model.

As a first step towards coupled WRF-Hydro simulations, the uncoupled WRF-Hydro calibration was carried out. The model reproduced the observed discharge at the Tana Rukanga RGS 4BE10, which is located at the mouth of MSS during the year 2012. The uncoupled WRF-Hydro registered good results of NSE $=0.62$, with, however, an underestimation of $40 \%$ of the observed discharge.

Prior to the analysis of the water balance components, the WRF-only and coupled WRF-Hydro models' performance in simulated precipitation were compared to station data sourced from the stations located in MSS and also to TRMM and CHIRPS datasets. Both models showed reasonable correspondence with respect to the station data and the two gridded datasets. The models captured well the seasonal, annual, and interannual evolution of both datasets. The models exhibit similar performance most of the time especially on the 4year mean averages.

Results in simulated discharge for the coupled WRF-Hydro for the period 2011 to 2014 showed consistency with that simulated in uncoupled WRF-Hydro. The averaged simulated discharge $\left(34.7 \mathrm{~m}^{3} / \mathrm{s}\right)$ in the coupled case matched closely that recorded at RGS 4BE10 gauge $\left(36 \mathrm{~m}^{3} / \mathrm{s}\right)$.

The simulated water balance components in the WRF-only and coupled WRF-Hydro exhibited similar seasonal, annual, and interannual variability for the period 2011 to 2014. Most of the components had their peak during April/May and November. This was influenced by the moisture transport into the study area. The smallest variation was for the case of evapotranspiration (ET) and atmospheric water storage $(d W / d t)$. During the rainy seasons of MAM and OND, the soils were replenished with enough moisture as $P>\mathrm{ET}$ as well as the associated water vapor convergence. ET in this region was seen to be playing a greater role during the dry months (JanuaryMarch) with associated atmospheric divergence. Among the water balance tendencies, the terrestrial water storage, $d S / d t$, did not tend towards zero even after 1 year or the entire period of study. However, $d W / d t$ tended to zero in period in month duration and became negligible in annual or longer.

The intensity of the water cycle has been quantified in terms of recycling ratio and precipitation efficiency. On the monthly scale, the magnitude of the recycling ratio was small, ranging from 0.0 to 0.04 , while that of precipitation efficiency ranged between 0.0 and 0.07 . This indicates that precipitation in this region during this period mainly originates from water vapor inflow at the lateral boundaries of the domain, so that potential land-precipitation feedback mechanisms have a reduced impact in this region at this scale.

Based on our research study, compared to WRF-only, the coupled WRF-Hydro slightly reduces precipitation, evapotranspiration, and the soil water storage but increases runoff. Thus, the impact of coupled WRF-Hydro in simulation of runoff shows deviation from expectation, probably because of the strong orographic forcing in our region. Further, the magnitude and differences between land-atmospheric feedback mechanisms, which include the precipitation efficiency and recycling ratio, are small.

The coupled WRF-Hydro serves as a tool in quantifying the atmospheric-TWB for this region. Further studies with a larger area covering the whole of TRB and East Africa would allow testing the impact of local recycling at larger scales and improve our understanding of land-atmosphere feedback mechanisms. In the long run, such studies may lead to suggestions of better management practices of the scarce water resources over the region.

Acknowledgements We acknowledge the financial support for this work from the German Academic Exchange Service (DAAD) and the National Commission for Science, Technology and Innovation (NACOSTI) on behalf of the government of Kenya. Dr. Arnault was funded by DFG within the subproject "A5-The role of soil moisture and surface- and subsurface water flows on predictability of convection" of the Transregional Collaborative Research Center SFB/TRR 165 "Waves To Weather." Further, we acknowledge support by the WASCAL project funded by the German Ministry of Education and Research (BMBF).

We appreciate the Leibniz Supercomputing Centre (LRZ) and the Karlsruhe Institute of Technology and its Institute of Meteorology and Climate Research Atmospheric Environmental Research (KIT/IMK-IFU), Campus Alpin, for providing library and computing facilities. We also like to thank the European Centre for Medium-Range Weather Forecasts (ECMWF) for providing the ERA-Interim reanalysis data and products.

We recognize the Kenya Meteorological Services (KMS) for providing the monthly rainfall data and the Kenya Water Resource Management Authority (WRMA) for providing discharge data, rainfall data, and the shape files used in this study. We thank the two anonymous reviewers for their valuable comments.

Open Access This article is distributed under the terms of the Creative Commons Attribution 4.0 International License (http:// creativecommons.org/licenses/by/4.0/), which permits unrestricted use, distribution, and reproduction in any medium, provided you give appropriate credit to the original author(s) and the source, provide a link to the Creative Commons license, and indicate if changes were made. 


\section{References}

Agwata JF (2005) Water resources utilization, conflicts and interventions in the Tana Basin of Kenya. Fwu, 3(Topics of Integrated Watershed Management-Proceedings) 13-23

Anyah RO, Weaver CP, Miguez-Macho G, Fan Y, Robock A (2008) Incorporating water table dynamics in climate modeling: 3. Simulated groundwater influence on coupled land-atmosphere variability. Journal of Geophysical Research Atmospheres 113(7):1-15. doi:10.1029/2007JD009087

Arnault J, Wagner S, Rummler T, Fersch B, Bliefernicht J, Andresen S, Kunstmann H (2016) Role of runoff-infiltration partitioning and resolved overland flow on land-atmosphere feedbacks: a casestudy with the WRF-Hydro coupled modeling system for West Africa. J Hydrometeorol 17:1489-1516. doi:10.1175/JHM-D-150089.1

Asharaf S, Dobler A, Ahrens B (2012) Soil moisture-precipitation feedback processes in the Indian summer monsoon season. $J$ Hydrometeorol 13(1989):1461-1474. doi:10.1175/JHM-D-12-06.1

Bronstert A, Carrera J, Kabat P, Lütkemeier S (eds) (2005) Coupled models for the hydrological cycle. Springer, Berlin

Chen F, Dudhia J (2001) Coupling an advanced land surface-hydrology model with the Penn State-NCAR MM5 modeling system. Part I: model implementation and sensitivity. Mon Weather Rev 129(4): 569-585. doi:10.1175/1520-0493(2001)129<0569:CAALSH>2.0. $\mathrm{CO} ; 2$

Chou M-D, Suarez MJ (1999) A solar radiation parameterization for atmospheric studies. NASA Technical Report 104606, 15(June), 40

Dee DP, Uppala SM, Simmons AJ et al (2011) The ERA-Interim reanalysis: configuration and performance of the data assimilation system. Q J R Meteorol Soc 137(656):553-597. doi:10.1002/qj.828

Draper C, Mills G (2008) The atmospheric water balance over the semiarid Murray-Darling River basin. J Hydrometeorol 9(3):521-534. doi:10.1175/2007JHM889.1

Eltahir EAB, Bras RL (1996) Precipitation recycling. Rev Geophys 34: 367-378

Endris SH, Omondi P, Jain S, Lennard C, Hewitson B, Chang'a L, Awange JL (2013) Assessment of the performance of CORDEX regional climate models in simulating East African rainfall. J Clim 26:8453-8475. doi:10.1175/JCLI-D-12-00708.1

Findell KL, Eltahir EAB (2003) Atmospheric controls on soil moistureboundary layer interactions. Part I: framework development. J Hydrometeorol 4(3):552-569. doi:10.1175/1525-7541(2003)004 $<0552$ :ACOSML $>2.0$.CO;2

Friedl M, McIver D, Hodges JC, Zhang X, Muchoney D, Strahler A, Woodcock C, Gopal S, Schneider A, Cooper A, Baccini A, Gao F, Schaaf C (2002) Global land cover mapping from MODIS: algorithms and early results. Remote Sens Environ 83(1-2):287-302. doi: 10.1016/S0034-4257(02)00078-0

Funk C, Verdin A, Michaelsen J, Peterson P, Pedreros D (2015) Husak G. A global satellite-assisted precipitation climatology 7:275-287. doi:10.5194/essd-7-275-2015

Geertsma R, Wilschut LI, Kauffman JH (2009) Baseline review of the Upper Tana, Kenya. Green Water Credits Report 8. Wageningen

Gochis D, Yu W, Yates D (2015) The WRF-Hydro model technical description and user's guide, version 3.0. NCAR Technical Document. 120 pages, (May). Available at: http://www.ral.ucar. edu/projects/wrf_hydro/

Hong S-Y, Noh Y, Dudhia J (2006) A new vertical diffusion package with an explicit treatment of entrainment processes. Mon Weather Rev 134(9):2318-2341. doi:10.1175/MWR3199.1

Huffman GJ, Bolvin DT, Nelkin EJ, Wolff DB, Adler RF, Gu G, Hong Y, Bowman KP, Stocker EF (2007) The TRMM Multisatellite Precipitation Analysis (TMPA): quasi-global, multiyear, combined-sensor precipitation estimates at fine scales. J Hydrometeorol 8:38-55. doi:10.1175/JHM560.1

Kain JS (2004) The Kain-Fritsch convective parameterization: an update. J Appl Meteorol 43(1):170-181. doi:10.1175/1520-0450(2004)043 $<0170$ :TKCPAU>2.0.CO;2

Kerandi NM, Laux P, Arnault J, Kunstmann H (2016) Performance of the WRF model to simulate the seasonal and interannual variability of hydrometeorological variables in East Africa: a case study for the Tana River basin in Kenya. Theor Appl Climatol. doi:10.1007 /s00704-016-1890-y

Kitheka JU, Obiero M, Nthenge P (2005) River discharge, sediment transport and exchange in the Tana Estuary, Kenya. Estuar Coast Shelf Sci 63(3):455-468. doi:10.1016/j.ecss.2004.11.011

Koster RD, Dirmeyer PA, Guo Z, Bonan G, Chan E, Cox P, Gordon CT, Kanae S, Kowalczyk E, Lawrence D, Liu P, Lu C-H, Malyshev S, McAvaney B, Mitchell K, Mocko D, Oki T, Oleson K, Pitman A, Sud YC, Taylor CM, Verseghy D, Vasic R, Xue Y, Yamada T (2004) Regions of strong coupling between soil moisture and precipitation. Science 305(5687):1138-1140. doi:10.1126/science.1100217

Krhoda GO (2006) Kenya National Water Development Report. 1-244. Available at: unesdoc.unesco.org/images/0014/001488/148866e. pdf

Kunstmann H, Jung G (2007) Influence of soil-moisture and land use change on precipitation in the Volta Basin of West Africa. International Journal of River Basin Management 5(1):9-16. doi:10.1080/15715124.2007.9635301

Kunstmann H, Stadler C (2005) High resolution distributed atmospherichydrological modelling for Alpine catchments. J Hydrol 314(1-4): 105-124. doi:10.1016/j.jhydrol.2005.03.033

Maingi JK, Marsh SE (2002) Quantifying hydrologic impacts following dam construction along the Tana River, Kenya. J Arid Environ 50(1):53-79. doi:10.1006/jare.2000.0860

Mango LM, Melesse AM, McClain ME, Gann D, Setegn SG (2011) Land use and climate change impacts on the hydrology of the upper Mara River Basin, Kenya: results of a modeling study to support better resource management. Hydrol Earth Syst Sci 15(7):2245-2258. doi:10.5194/hess-15-2245-2011

Maxwell RM, Katopodes F, Kollet SJ (2007) The groundwater-landsurface-atmosphere connection : soil moisture effects on the atmospheric boundary layer in fully-coupled simulations. Adv Water Resour 30:2447-2466. doi: 10.1016/j.advwatres.2007.05.018

Maxwell RM, Lundquist JK, Mirocha JD, Smith SG, Woodward CS, Tompson AFB (2011) Development of a coupled groundwater-atmosphere model. Mon Weather Rev 139(2005):96-116. doi:10.1175/2010MWR3392.1

Monin AS, Obukhov AM (1954) Basic laws of turbulent mixing in the surface layer of the atmosphere Contrib. Geophys Inst Acad Sci USSR 24(151):163-187

Moriasi DN, Arnold JG, Van Liew MW, Binger RL, Harmel RD, Veith TL (2007) Model evaluation guidelines for systematic quantification of accuracy in watershed simulations. Trans ASABE 50(3):885-900

Music B, Caya D (2007) Evaluation of the hydrological cycle over the Mississippi River Basin as simulated by the Canadian Regional Climate Model (CRCM). J Hydrometeorol 8(5):969-988. doi:10.1175/JHM627.1

Nakaegawa T, Wachana C (2012) First impact assessment of hydrological cycle in the Tana River Basin, Kenya, under a changing climate in the late 21st century. Hydrological Research Letters 6:29-34. doi:10.3178/hrl.6.29

Niang I, Ruppel OC, Abdrabo MA, Essel A, Lennard C, Padgham J, Urquhart P (2014) Africa, climate change 2014: impacts, adaptation and vulnerability - Contributions of the Working Group II to the Fifth Assessment Report of the Intergovernmental Panel on Climate Change. 1199-1265. Available at: https://ipcc-wg2. gov/AR5/images/uploads/WGIIAR5-Chap22_FINAL.pdf 
Obiero JPO (2011) Modelling of streamflow of a catchment in Kenya. Journal of Water Resource and Protection 3(9):667-677. doi:10.4236/jwarp.2011.39077

Oki T, Musiake K, Matsuyama H, Masuda K (1995) Global atmospheric water balance and runoff from large river basins. Hydrol Process 9(1994):655-678. doi:10.1002/hyp.3360090513

Oludhe C, Sankarasubramanian A, Sinha T, Devineni N, Lall U (2013) The role of multimodel climate forecasts in improving water and energy management over the Tana River basin, Kenya. J Appl Meteorol Climatol 52(11):2460-2475. doi:10.1175/JAMC-D-120300.1

Peixoto JP, Oort AH (1992) Physics of climate. American Institute of Physics, New York

Pleim JE (2007) A combined local and nonlocal closure model for the atmospheric boundary layer. Part I: model description and testing. J Appl Meteorol Climatol 46(9):1383-1395. doi:10.1175/JAM2539.1

Roberts J, Snelgrove K (2015) Atmospheric and terrestrial water balances of Labrador's Churchill River Basin, as simulated by the North American Regional Climate Change Assessment Program. Atmosphere-Ocean 53(3):304-318. doi:10.1080/07055900.2015.1029870

Schär C, Lüthi D, Beyerle U, Heise E (1999) The soil-precipitation feedback: a process study with a regional climate model. J Clim 12(2-3): 722-741. doi:10.1175/1520-0442(1999)012<0722:TSPFAP $>2.0$. $\mathrm{CO} ; 2$

Senatore A, Mendicino G, Gochis DJ, Yu W, Yates DN, Kunstmann H (2015) Fully coupled atmosphere-hydrology simulations for the Central Mediterranean: impact of enhanced hydrological parameterization for short and long time scales. Journal of Advances in Modeling Earth Systems 1-23. doi: 10.1002/2015MS000510

Shelton ML (2009) Hydroclimatology: perspectives and applications, 1st edn. Cambridge University Press, Cambridge

Shrestha P, Sulis M, Masbou M, Kollet S Simmer C (2014) A scaleconsistent Terrestrial Systems Modeling Platform based on COSMO, CLM and ParFlow. Monthly Weather Review 140422120610007. doi: 10.1175/MWR-D-14-00029.1
Skamarock WC, Klemp JB, Dudhi J, Gill DO, Barker DM, Duda MG, Huang X-Y, Wang W, Powers JG (2008) A description of the Advanced Research WRF Version 3. Technical Report 113. doi: 10.5065/D6DZ069T

Trenberth KE (1999) Atmospheric moisture recycling: role of advection and local evaporation. J Clim 12(5 II):1368-1381. doi:10.1175 1520-0442(1999)012<1368:AMRROA>2.0.CO;2

Wagner S, Fersch B, Yuan F, Yu Z, Kunstmann H (2016) Fully coupled atmospheric-hydrological modeling at regional and long-term scales: development, application, and analysis of WRF-HMS. Water Resour Res 52:1-20. doi:10.1002/2015WR018185

Williams AP, Funk C (2011) A westward extension of the warm pool leads to a westward extension of the Walker circulation, drying eastern Africa. Clim Dyn 37(11-12):2417-2435. doi:10.1007 /s00382-010-0984-y

Wilschut LI (2010) Land use in the Upper Tana catchment. Wageningen, Kenya Technical report of a remote sensing based land use map

Yeh PJF, Famiglietti JS (2008) Regional terrestrial water storage change and evapotranspiration from terrestrial and atmospheric water balance computations. Journal of Geophysical Research Atmospheres 113(9):1-13. doi:10.1029/2007JD009045

Yeh PJF, Irizarry M, Eltahir EAB (1998) Hydroclimatology of Illinois: a comparison of monthly evaporation estimates based on atmospheric water balance and soil water balance. J Geophys Res 103:19,82319,837

Yucel I, Onen A, Yilmaz KK, Gochis DJ, (2015) Calibration and evaluation of a flood forecasting system: utility of numerical weather prediction model, data assimilation and satellite-based rainfall. Journal of Hydrology Elsevier B.V. 523: 49-66. doi: 10.1016/j. jhydrol.2015.01.042

Zabel F, Mauser W (2013) 2-way coupling the hydrological land surface model PROMET with the regional climate model MM5. Hydrol Earth Syst Sci 17(5):1705-1714. doi:10.5194/hess-17-1705-2013 